\title{
Fundamentos del Psicoanálisis Relacional: Filogenia y ontogenia ${ }^{1}$
}

\author{
Dr. Mauricio Cortina \\ Attachment and Human Development Center, Washington School of Psychiatry, Washington, DC, \\ Seminario de sociopsicoanalisis, A.C. México DF, México; \\ Institute for Contemporary Psychotherapy and Psychoanalysis, Washington, DC
}

El psicoanálisis relacional emerge como un dialogo entre teorías de relaciones objétales que surgen en la Gran Bretaña y teorías de relaciones interpersonales y algunos representantes de la self psychology que surgen en los Estados Unidos. La pluralidad de voces y una actitud más abierta, autentica, flexible y cooperativa del dialogo clínico de este giro relacional es uno de sus logros más importantes. Pero con pocas excepciones, la posibilidad de crear una integración ha quedado rezagado como meta, e inclusive para algunos, una mata indeseable. Esta posición se basa en creencia de que la cacofonía de voces del psicoanálisis contemporáneo y su eclecticismo actual evita caer en dogmatismos que han caracterizado la historia del psicoanálisis. Lejos de ser una amenaza, esfuerzos integrativos son esenciales para crear un dialogo más productivo dentro del psicoanálisis relacional y crear terapias más efectivas. Una parte muy importante de esta integración debe incluir una visión de que es lo que nos hizo humanos.

Desde las primeras especulaciones de Freud sobre la relación entre la filogenia y la ontogenia el tema ha sido desatendido. Este ensayo tiene dos tesis centrales. Primero, que el producto principal de nuestra herencia filogenética es haber creado una mente construida para poder comunicar y compartir experiencias basados en gestos, emociones, motivaciones y valores en común, creando una forma de ultracooperación que caracteriza a nuestra especie. La combinación de estas capacidades de una mente construida para cooperar y comunicar mediante un proto-lenguaje basado en gestos e imitación (mimesis) creo un tipo nuevo de evolución, la evolución cultural. La evolución cultural co-evolucionó con la evolución biológica. La evolución biológica funciona mediante presiones selectivas que operan a nivel genético que favorecen aquellos genes y fenotipos más adaptados a sobrevivir en ambientes específicos. La evolución cultural está basada en presiones selectivas que operan a nivel de grupos y que favorecen grupos más flexibles y cooperativos que compiten favorablemente por con grupos menos flexibles y cooperativos. La información y conocimiento adquirida por grupos más cooperativos y flexibles se transmite culturalmente y se va acumulando a través de miles de generaciones. Estas dos formas de evolución empezaron a influirse mutuamente hace 100,000 años, o tal vez mucho antes, creando las condiciones favorables para la emergencia de capacidades simbólicas y la aparición del lenguaje. El resultado ha sido una flexibilidad adaptativa y una capacidad de auto-transformación de nuestra especie sin paralelo en la naturaleza.

La segunda tesis de este ensayo es que podemos ver manifestaciones de las bases socio-biológicas y culturales de nuestra especie claramente en el desarrollo ontogenético. Esto no es un argumento mecanicista simple de que la ontogenia recapitula la filogenia directamente como lo pensó Freud, sino más bien que podemos ver en la ontogenia temprana las huellas de las motivaciones socioemocionales y capacidades sociocognitivas y normativas que nos hicieron humanos, y podemos ver en la filogenia los efectos de modificaciones de la ontogenia. Las relaciones entre la filogenia y ontogenia son complexa bidireccionales. Concluyo con algunas observaciones preliminares señalando como las motivaciones y capacidades de nuestra mente cooperativa, comunicativa y compartida son esenciales para el ejercicio de terapias de tipo relacional.

Palabras clave: filogenia, ontogenia, patrimonio evolutivo, evolución biológica, psicoanálisis relacional.

\footnotetext{
${ }^{1}$ Una versión previa de este trabajo fue leída como conferencia principal en las VIII Jornadas Bienales de IARPPEspaña en Sevilla, 19 de Octubre de 2019, como Segunda Ponencia: Fundamentos evolutivos del psicoanálisis relacional. Actuó como moderadora: Rosa Domínguez
} 
Relational psychoanalysis emerged as a dialogue between object relational theories in the United Kingdom and interpersonal and self psychological theories in the United States. A plurality of voices and a more open, authentic, flexible and cooperative dialogue are some its greatest strengths. But with few exceptions the possibility of creating an integration has been neglected, and for some this project is not even considered a desirable goal. That position is based on the belief that the cacophony of voices of relational psychoanalysis and its eclecticism prevents us from falling back into the dogmatism that has characterized the history of psychoanalysis. Rather than being a threat, integrative efforts will create a more productive dialogue within relational approaches to psychotherapy and better outcomes. A very important part of this integration is understanding what made us human.

Since Freud's speculations about the relation between phylogeny and ontogeny, this important relation has been with completely neglected in psychoanalysis and the mental health field. There are two central theses of this essay. First, the main outcome of our evolutionary heritage was to create a cooperative mind built to communicate and share experiences based on gestures, emotions, motivations, socio-cognitive capacities and social norms. The combination of these motivations and capacities and a proto-language based on gestures and imitation (mimesis) created a new form of evolution, cultural evolution. Biological evolution co-evolved with cultural evolution. Biological evolution is based on selective pressures that operate at the level of genes and favor genes and phenotypes that are better adapted to survive in specific environments. Cultural evolution is based on selective pressures that operate at the level of groups that favored flexible and cooperative groups that compete successfully for resources over less flexible and cooperative groups. The information and knowledge acquired from the more cooperative groups is transmitted culturally and accumulates over thousands of generations. These two forms of evolution began to influence each other 100,000 years ago, or perhaps much earlier, when most experts believe symbolic capacities and language emerged. The result has been to create a degree of adaptive flexibility and self-transformative capacity in our species without parallel in nature.

The second theses of this essay is that we can see manifestations of our evolutionary history during early development. This is not a simple mechanistic view that ontogeny recapitulates phylogeny directly as Freud believed, but rather that we can see the footprints during early development of socioemotional motivations, sociocognitive and normative capacities that made us human. Furthermore, the relations between phylogeny and ontogeny are complex and influence each other. I conclude with some preliminary comments describing how these motivations and capacities of a cooperative, communicative and shared mind are essential for the practice of relationally-based psychotherapies.

Key Words: phylogeny, ontogeny, evolutionary heritage, Biological evolution, Relational Psychoanalysis English Title: Foundations of Relational Psychoanalysis: Phylogeny and ontogeny

\section{Cita bibliográfica / Reference citation:}

Cortina, M. (2020). Fundamentos del Psicoanálisis Relacional: Filogenia y ontogenia. Clínica e Investigación Relacional, 14 (1): 12-54. [ISSN 1988-2939] [Recuperado de www.ceir.info ] DOI: 10.21110/19882939.2020.140101

\section{CeIR Vol. 14 (1) - Abril 2020 ISSN 1988-2939 - www.ceir.info}

@ Derechos reservados/Copyright de Clínica e investigación Relacional y los autores. Prohibida la reproducción total o parcial sin autorización expresa. Este material es para uso científico y profesional exclusivamente y puede contener información clínica sensible. Los editores no se responsabilizan de los contenidos de los autores. Dirigir las consultas sobre derechos y autorizaciones a ceir@psicoterapiarelacional.es 


\section{Introducción}

La sobrevivencia de nuestra especie requirió convertirnos en un ser ultrasocial y ultracooperativo. Esta tesis tal vez sorprenda a muchos acostumbrados a ver la selección natural como una batalla campal competitiva y muchas veces violenta. Pero lo que una ciencia nueva multidisciplinaria evolutiva nos está enseñando es que en algunas especies ultrasociales, como las termitas y las hormigas y nuestra especie, una cooperación y altruismo extensa han sido claves para su éxito (E. O. Wilson, 2012, 2014). La aparición de especies ultrasociables es un fenómeno raro, requiriendo que una serie de circunstancias se alinean para su emergencia ${ }^{1}$. Pero una vez que esto sucede, el dominio de la ultrasociabilidad sobre otras especies menos sociales es avasallador. Una diferencia fundamental con la ultrasociabilidad de los insectos ultrasociales y nuestra especie es que los insectos logran altos niveles de cooperación grupal perdiendo la individualidad de sus miembros, que operan más bien como células de un superorganismo social. En cambio, los humanos alcanzamos un alto grado de ultrasociabilidad y cooperación manteniendo la individualidad de cada miembro del grupo-con variaciones culturales e históricas muy importantes (E. O. Wilson, 2012). Este ensayo es una introducción de cómo nuestra especie logró obtener este tipo nivel de ultrasociabilidad y ultracooperacion, cómo se manifiestan estas capacidades durante la ontogenia temprana, y una exploración preliminar de su importancia para nuestra concepción de la naturaleza humana y el psicoanálisis relacional.

Es importante notar que la ultrasociabilidad y ultracooperación de nuestra especie no minimiza la importancia del egoísmo y la competencia. Pero el egoísmo, como veremos, está combinado con un altruismo extenso, y la competencia adquiere características nuevas. No sólo ocurre a nivel individual como en la gran mayoría de las especies, sino también a nivel de grupos y culturas (Boyd, 2018; Nowak \& Highfield, 2011; Sober \& Wilson, 1998; D. S. Wilson \& Wilson, 2007). Mas aun, esta competencia intergrupal e intercultural tiene una infraestructura cooperativa compleja y masiva que puede verse claramente en organizaciones humanas que compiten entre sí, como en organizaciones militares, en deportes organizados o en las leyes que regulan las economías de mercado (Bowles \& Gintis, 2011; Boyd, 2018; J. Henrich, 2016; Tomasello, 2016; E. O. Wilson, 2012). La combinación de competencia y cooperación masiva a nivel de grupos, organizaciones de diferente tipo o naciones, puede ser enormemente constructiva o destructiva, y es uno de los componentes de la naturaleza humana que nos hace un animal tan peligroso, con un genio para el bien y el mal.

Comienzo con una vista de vuelo de pájaro al giro relacional del psicoanálisis para después examinar como la ultrasociabilidad y ultracooperación de nuestra especie provee el fundamento evolutivo de este giro relacional. 


\section{El giro relacional del psicoanálisis contemporáneo}

Las teorías relacionales tienen su origen en Los Estados Unidos y la Gran Bretaña. En los Estados Unidos, A finales de la década de 1930 y principios de 1940 Harry Stack Sullivan (1953) junto con los emigrantes Europeos Erich Fromm (1945) y Karen Horney (1937) rechazan la teoría pulsional de Freud, substituyendo la libido con la enorme importancia de la experiencia interpersonal en el desarrollo de la personalidad. Otro elemento en común de estos autores es su gran interés en las influencias culturales que moldean la personalidad, pero difieren en sus posturas hacia estas influencias. Partiendo de un análisis marxista, Fromm ve las influencias culturales como una adaptación al modo de producción económico, y adopta una postura radicalmente crítica de la sociedad (Fromm, 1955). En cambio, la postura de Sullivan y Horney hacia las influencias culturales es más bien reformista que radical.

Al mismo tiempo que las corrientes interpersonales estaban empezando a aparecer en los Estados Unidos, del otro lado del Atlántico se estaba gestando una revisión similar en la Gran Bretaña con las aportaciones de Ronald Fairbairn (1952), Donald Winnicott (1969), Harry Guntrip (1971) y John Bowlby (1958) entre muchos otros. Los teóricos de las relaciones objetales difieren entre sí en muchos aspectos, pero coinciden en una revisión de la teoría pulsional de Freud y la importancia de las relaciones de objeto en el desarrollo de la personalidad.

Integrando las aportaciones de las teorías interpersonales en los Estados Unidos y las relaciones de objeto en la Gran Bretaña nace el movimiento relacional del psicoanálisis unas décadas después con las aportaciones seminales de Greenberg y Mitchell (1983) y de Mitchell (1988) y sus colaboradores (1999). La revisión relacional del psicoanálisis clásico centrado en Freud ha demolido la visión clásica de un analista experto que interpreta el inconsciente desde una postura emocionalmente objetiva y distante. El proceso analítico es intersubjetivo, intricado, complejo y muchas veces embrollado. Cada relación analista-paciente es única y singular. Necesariamente la terapia va a revelar vulnerabilidades en pacientes, pero también (Gallese, 2002)en los terapeutas, por muy bien analizados que hayan sido. Este cambio teórico ha tenido un efecto tajante en la práctica clínica y ha puesto la relación terapéutica en un primer plano como un factor primordial en el proceso de cambio (Flückiger, Del Re, Wampold, \& Horvath, 2018). El resultado es qué en manos de analistas competentes, las relaciones terapéuticas se han liberado de la ortodoxia clásica, volviéndose más abiertas, honestas, auténticas y empáticas con conceptos como los siguientes:

- La enorme importancia que los vínculos de apego durante el desarrollo en crear una base segura y de confianza para la exploración del mundo material y social (Ainsworth, Blehar, Waters, \& Wall, 1978; Bowlby, 1988; Cortina, 2013; L. A. Sroufe, Egeland, Carlson, \& Collins, 2005) 
- La mutualidad de la relación terapéutica, (Aron, 1996).

- La co-construcción de la relación terapéutica (Hoffman, 1998).

- El saber cómo acompañar a nuestros pacientes (Grossmark, 2016).

- La reciprocidad mutua y el desarrollo de un "tercero moral" (Benjamin, 1992, 2004)

- El analizar mostrando las cartas (Renik, 1999).

- Diálogos clínicos cooperativos y amigables (Lichtenberg, Lachmann, \& Fosshage, 1996)

- Improvisación e interacciones espontáneas (Ringstrom, 2001).

- Momentos de aquí y ahora que se convierten en momentos de encuentro ("now moments") (Stern, 2004).

- Una inmersión empática en el mundo de los pacientes (Kohut, 1977, 1984)

- Modos implícitos (subsimbólicos) y explícitos (simbólicos) de conocernos a nosotros mismos y a los demás (Bucci, 2005; Cortina \& Liotti, 2007; Fosshage, 2005)

- Interpretaciones transferenciales que se ubican en el pasado y aquellas que apuntan hacia cambios y potencialidades en el futuros (forward edge and trailing edge transference) (Tolpin, 2002).

- Enactments, un concepto que pone atención a re-escenificaciones provenientes de la infancia que se actualizan en la terapia. El concepto de enactment fue propuesto por Theodore Jacobs (Jacobs, 1986) ha sido comentado y elaborado por muchos analistas relacionales - ver la discusión de Aron (Aron, 2003).

- Conceptos de mentalizacion (Fonagy, Bateman, \& Luyten, 2012) y diálogos reflexivos (Marrone, 2001)

- El reconocimiento de vulnerabilidades mutuas que muchas veces determina el éxito o fracaso de terapias complicadas (Renik, 2007).

Las investigaciones de la importancia de los vínculos de apego son consistentes y apoyan científicamente muchos aspectos de este giro relacional del psicoanálisis contemporáneo (Cortina, 2018a; Cortina \& Marrone, 2017; Marrone, 2001; S.A. Mitchell, 1998; L. A. Sroufe, 1996; L. A. Sroufe et al., 2005). Asimismo, las investigaciones sobre comunicaciones intersubjetivas entre infantes con sus madres apoyan este giro relacional del psicoanálisis relacional e intersubjetivo (Beebe, Knoblauch, Rustin, \& Sorter, 2005; Reddy, 2008; Stern, 2006; Trevarthen, 1979, 1980; Tronick, 2007). Finalmente, la neurociencia contemporánea es en líneas generales consistente con estos cambios (Gallese, 2002; Panksepp, 1998; Schore, 2009; Siegel, 1999). Con esta reseña breve del giro relacional del psicoanálisis y para entrar al tema de sus bases evolutivas comienzo por examinar el papel de los instintos en el psicoanálisis en las obras de Sigmund Freud, Erich Fromm y John Bowlby. 


\section{Una propuesta dialéctica sobre el papel que juegan los instintos en el psicoanálisis}

La concepción de instintos primitivos y arcaicos de la obra de Freud es típica de las sociedades burguesas y victorianas de finales del siglo 19 y principios del siglo 20 que emergen después de la revolución industrial. Influidas por los filósofos de la ilustración, las sociedades victorianas apuestan en la razón en poder controlar impulsos destructivos que atribuyen a nuestro legado filogenético primitivo. Típico de este tipo de pensamiento es el uso que hace Freud de teoría de selección natural y las ideas evolucionistas de su tiempo. Freud piensa que la expresión de instintos incestuosos y agresivos son una herencia filogenética primitiva que gradualmente es controlada mediante su represión y/o sublimación durante el curso "civilizador" de la historia. Basado en Lamarck, las características adquiridas durante la ontogenia se podían heredar así como que la filogenia se repite en la ontogenia-propuestas famosas hechas por un biólogo del siglo XIX, Ernest Haeckel (S. J. Gould, 1977; Sulloway, 1979). ${ }^{2}$ Freud propone que la represión de instintos agresivos e incestuosos se repite durante la ontogenia culminando en la resolución del complejo de Edipo (Freud, 1913, 1930). Esta visión de Freud esta encapsulada en su lema "donde había ello, yo habrá".

De acuerdo a Fromm, nuestro equipaje instintivo ha disminuido durante el transcurso de la evolución a un mínimo y es sustituido por un crecimiento enorme de la corteza frontal y la necesidad de adaptarse a ambientes sociales y culturales que los humanos creamos (Fromm, 1947). Fromm piensa que el origen de la destructividad humana no reside en la represión o sublimación de instintos primitivos y agresivos, sino en adaptaciones a sociedades explotadores y deshumanizantes (Fromm, 1973). Si tratáramos de encapsular esta visión de Fromm diríamos "donde había instintos que guiaban nuestra conducta, habrá adaptaciones a condiciones socioeconómicas y culturales". Estos adaptaciones se internalizan, ya sea para el bien o para el mal, y se convierten en rasgos de carácter y valores compartidos por diferentes grupos y clases sociales-su concepto de carácter social (Fromm, 1955, 1970).

Bowlby propone una manera nueva de abordar el tema de los instintos basado en el estudio de comportamiento en animales. Bowlby nota que en la gran mayoría de los mamíferos y en algunas especies de pájaros emergen dos instintos psicosociales con conductas complementarias: la búsqueda de la protección en momento de peligro por parte de los miembros juveniles de estas especies (el apego propiamente dicho), y el cuidado y protección, muchas veces feroz, de sus madres en proteger a sus críos (Bowlby, 1969/1982). Juntos, el apego y el sistema de protección y cuidado crean una relación o vinculo de apego. Estos vínculos y la base de seguridad que crean condiciones óptimas para la exploración del mundo social y material (Ainsworth et al., 1978; Bowlby, 1988). Bowlby ve una continuidad de instintos prosociales que 
nos une con otras especies, y por ello su propuesta representa un inicio de una síntesis dialéctica de las posiciones opuestas de Freud y Fromm.

A pesar de esta aportación fundamental de Bowlby, la teoría de apego por sí sola no es una explicación del tema de que es lo que nos hizo humanos. Muchas otras especies de mamíferos forman vínculos afectivos de apego. ¿Por qué entonces solo los humanos hemos podido desarrollar este grado de ultrasociabilidad y ultracooperación que ha sido la base de acumulación de conocimiento cultural durante los últimos 100,000 años? La teoría e investigación de apego, con una mira a la filogenia y otro en a la ontogenia, nos proporciona una llave y un método para para empezar indagar este tema fascinante. Usemos esta llave y método para ver que puertas nos puede abrir.

\section{La filogenia de nuestra especie ¿Que nos hizo humanos?}

En el momento en que nos preguntamos qué es lo que nos hizo diferentes como especie aparece una respuesta que está a la vista de todos: el lenguaje y nuestras capacidades simbólicas y de imaginación. Una tesis central de este ensayo es que para que emergiera el lenguaje y el pensamiento cognitivo y simbólico avanzado, tuvo que haber una transformación emocional y relacional previa de nuestros antecesores humanos. Como explicaré a continuación, esta transformación emocional y relacional contiene componentes motivacionales, socio-cognitivos y normativos. (Cortina, 2017; S. Hrdy, 2009; S. Hrdy, 2016; Laland, 2017; Tomasello, 2019; Tomasello, Melis, Tennie, Wyman, \& Herrmann, 2012).

\section{Un cambio de paradigma de las teorías sobre la evolución}

Esta visión nueva de la naturaleza ultracooperativa y prosocial de nuestra especie no hubiese tenido la aceptación creciente que tiene sin una revisión de paradigma evolutivo imperante. Este paradigma, conocido como la "gran síntesis", apareció a mediados del siglo pasado y ha tenido un impacto enorme avanzando el entendimiento de los mecanismos de selección natural. El paradigma por primera vez integró el modelo de selección natural de Darwin (que desconocía los mecánicos de transmisión hereditaria) con los descubrimientos de las leyes de herencia genética descubiertas por Mendel, junto con modelos matemáticos que conciben a las mutaciones genéticas que se dan al azar en organismos dentro de un contexto de poblaciones. Aquellas variaciones alélicas (cada gene tiene dos alelos) que resultan ser adaptativas producen más sobrevivientes (la selección natural de Darwin). Una extensión de este paradigma en la sociobiología, por primera vez logró un avance importante en entendimiento de la aparición de altruismo en especies (Alexander, 1974; Hamilton, 1964; Williams, 1966). La idea es que el 
altruismo evolucionó porque el costo individual de conductas altruistas es compensado en la medida que beneficia a familiares: entre más cercano es el miembro familiar más probable que los genes del donador van a ser pasados a un recipiente familiar con el cual comparte muchos genes en común. Por ello, este mecanismo de selección natural es llamado selección familiar o selección inclusiva (Hamilton, 1963). A pesar de sus grandes aportes, el énfasis de la gran síntesis centrada exclusivamente en variaciones a nivel genético omitió varias dimensiones y mecanismos de cambios evolutivos muy importantes. A saber:

1. Que los organismos son agentes de su propia evolución y no solo vehículos pasivos que responden a mutaciones genéticas que se dan al azar (S. J. Gould \& Lewontin, 1979; Lewontin, 1978).

2. Los procesos de selección natural no sólo ocurren a nivel genético sino a niveles epigenéticos. Las modificaciones epigenéticas son de varios tipos y tienen efectos muy importantes. Por ejemplo, pueden modificar la capacidad de los organismos de cambiar el curso de su desarrollo ontogenético en comparación con otras especies de mamíferos. Un ejemplo es que tenemos en algunas áreas con un desarrollo extremadamente lento y en otras un desarrollo rápido en comparación con otras especies cercanas a la nuestra. Una expresión de la lentitud es que no maduramos sexualmente hasta la adolescencia. De hecho, nuestro desarrollo ontogenético ha insertado dos fases de desarrollo, la niñez y la adolescencia, que no tienen otros mamíferos que solo tiene dos fases de desarrollo, una fase infantil y una juvenil. Existe un consenso científico de que este enorme retraso en la maduración de muchos aspectos en nuestra desarrollo fue seleccionada para dar más tiempo a los infantes y niños de mantener una flexibilidad adaptativa necesaria para asimilar la enorme cantidad de conocimiento que necesitan para adaptarse a ambientes culturales (Bjorklund \& Rosenberg, 2005). En otras áreas tenemos un desarrollo muy acelerado, con una infancia muy corta y crecimiento cerebral extremadamente rápido durante el primer año de vida.

3. También hay un consenso general que la gran síntesis ignora la relación importante entre mecanismos de selección natural con el desarrollo (Gottlieb, 2007; Jablonka \& Lamb, 2005; West-Eberhard, 2003). Esta síntesis ha creado un nuevo campo de investigación designado en inglés como evolution and development (evolución y desarrollo) conocido también como evo-devo en corto.

4. Los efectos epigenéticos pueden ser rápidos y tener efectos macro-evolutivos (efectos mayores), y no sólo micro-evolutivos menores y graduales como propone la gran síntesis (Gottlieb, 2007; Jablonka \& Lamb, 2005; West-Eberhard, 2003).

5. El énfasis exclusivo de adaptación a nivel genética individual de la gran síntesis omite la importancia que pueden tener adaptaciones a nivel de grupos o culturas (Sober $\&$ Wilson, 1998; D. S. Wilson \& Wilson, 2007; E. O. Wilson, 2012). La idea central es que altos grados de altruismo evolucionaron en grupos, porque grupos con más miembros altruistas y cooperadores van a competir favorablemente con grupos, que menos individuos 
altruistas y cooperadores (Bowles \& Gintis, 2011; Boyd, 2018; N. Henrich \& Henrich, 2007; Richerson \& Boyd, 2005; Tomasello, Carpenter, Call, Behne, \& Henrike, 2005). Una consecuencia del antagonismo de representantes de la gran síntesis en contra de ideas de selección a nivel de grupo es la dificultad en explicar el altruismo y cooperación avanzada en grupos humanos que no están relacionados genéticamente como propone la selección familiar de Hamilton. ${ }^{3}$

Una implicación importante de estos principios en lo que atañe a la evolución humana es que la evolución a nivel genético y la evolución a nivel de grupos o culturas juegan un papel esencial, creando dos tipos de herencia que operan simultáneamente: la herencia genética enfatizada por la gran síntesis, y un nuevo tipo de herencia y evolución de tipo cultural. Así como hay una gran cantidad de información transmitida fielmente de una generación a otra por medio de genes, también hay una enorme cantidad de información cultural que se transmite fielmente por medio de la enseñanza e imitación a través de miles de generaciones. Esta transmisión cultural ha tenido efectos espectaculares, que nos ha permitido como especies crear símbolos alfabéticos, matemáticos y musicales, y una serie de revoluciones sociales, culturales, tecnológicas y económicas. A su vez estos cambios culturales y sociales acaban teniendo efectos genéticos por medio de mecanismos de retroalimentación positivos (Boyd, 2018; Boyd \& Richerson, 2005; Cavalli-Sforza \& Feldman, 1981; N. Henrich \& Henrich, 2007; Jablonka \& Lamb, 2005; Laland, 2017). Estos cambios del paradigma no invalidan los enormes avances que significó la gran síntesis del siglo pasado. Pero ponen el modelo de evolución centrado exclusivamente en variaciones genéticas aleatorias dentro de un contexto mucho más amplio conocido como "la extensión de la gran síntesis" (Laland et al., 2015). Con este resumen escueto podemos entrar de lleno a la pregunta de qué otros tipos de vínculos afectivos, capacidades socio-cognitivas y normativas, nos hizo humanos.

\section{La filogenia de nuestra especie: el surgimiento de la modernidad emocional y relacional de nuestra especie}

Varios autores han propuesto modelos de la evolución de nuestra especie en que la cooperación juega un rol esencial (Bowles \& Gintis, 2011; Boyd \& Richerson, 2005; Fuentes, 2017; J. Henrich, 2016; Laland, 2017; E. O. Wilson, 2012). A continuación tomo el modelo propuesto por Michael Tomasello en varios de sus libros (Tomasello, 2014, 2016) en combinación con la propuesta de Sara Hrdy (S. Hrdy, 2009; S. Hrdy, 2016): una fase emocional relacional y sociocognitiva y una fase sociocognitiva simbólica que se acompañó con la aparición del lenguaje. 


\section{Fase emocional, relacional y sociocognitiva}

El concepto de la modernidad emocional de nuestra especies fue propuesto por Sarah Hardy que la concibe como un resultado de la crianza cooperativa (Hrdy, 1999, 2016) o crianza biocultural (Bogin, Bragg, \& Kuzawa, 2014) en donde las madres permiten que otras miembros cercanos de su grupo asistan en la alimentación y cuidado de su infante, llamados alomadres (S. Hrdy, 1999, 2016) . ${ }^{4}$ La crianza colectiva es un fenómeno relativamente raro. En los primates un tercio de las 200 especies tiene elementos de crianza cooperativa, pero solo unas cuantas especies de primates, los humanos y una especies de monos de Sudamérica, los titíes y capuchinos, tienen una crianza cooperativa extensa (Burkart, Hrdy, \& Van Schaic, 2009; Burkart \& Van Schaik, 2010; S. Hrdy, 1999). Las madres de la mayoría de especies de primates que no tienen una crianza cooperativa solo ellas tienen la carga de cuidar a sus críos, primordialmente por los índices de infanticidio altos en muchas especies de primates (Johnson \& Whiffen, 2003). Entre la familia de los simios a la que pertenecemos, somos la única especie con una crianza cooperativa. De acuerdo a Hrdy, la crianza cooperativa tuvo varios efectos en la evolución de nuestra especie. Mencionó tres de las más importantes 1. Liberó a las madres para poder contribuir a la busca de alimentos para la sobrevivencia de sus grupos 2. Redujo el tiempo entre un embarazo a otro, y con ello un crecimiento poblacional más rápido 3 . Y lo que tiene gran importante pare la tesis central de este ensayo, tuvo un efecto en los infantes que tuvieron que vincularse con múltiples cuidadores, creando presiones selectivas en los infantes que favorecieron su mayor desarrollo emocional y comunicativo. ${ }^{5}$

A pesar de su enorme importancia, la crianza cooperativa, no fue la única adaptación que nos llevó a convertirnos en seres ultrasociales y ultracooperadores. Hubo una serie de cambios climatológicos severos y adaptaciones nuevas que actuaron en sinergia con la crianza cooperativa para crear la ultrasociabilidad de nuestra especie:

- Cambios climáticos severos obligaron a nuestros antecesores humanos a adaptarse a medios ambientes nuevos durante la época del Pleistoceno (2,6 millones a 12,500 años) (deMenocal, 2004; Potts, 1999; Richerson \& Boyd, 2013). La necesidad a adaptarse a ambientes ecológicos cambiantes nuevos crea presiones selectivas en adoptar una flexibilidad adaptativa, y una mayor cooperación y solidaridad grupal para buscar alimentos en ambientes muy diferentes y cambiantes y defenderse de predadores más potentes que existen en estos ambientes nuevos. La disyuntiva que producen estos cambios climáticos severos fue cooperar en grupos o morir.

- A su vez los cambios climáticos ponen presiones selectivas en producir una transición de una organización social jerárquica basada en el domino y sumisión que caracteriza a los primates y la familia de los simios a que pertenecemos (los chimpancés, bonobos orangutanes y gorilas), a una organización social cooperativa basada en la igualdad y reciprocidad (Boehm, 1999, 2012; Tomasello, 2016). Esto no quiere decir que el potencial 
de organización jerárquica social desaprecio. La jerarquía reaparece en forma transformada en sociedades agrícolas en formas complejas de instituciones y castas sociales cinco milenios después de la invención de la agricultura y la aparición de poblaciones sedentarias hace 10,000 años. Esto es un fenómeno reciente. Durante 2 millones de años con la aparición de las primeras especies de la familia Homo-ocho descubiertas hasta ahora-de las cuales somos los únicos sobrevivientes, vivimos en sociedades pequeñas de cazadores y recolectores nómades de 15 a 50 miembros que se relacionaban con otros grupos similares en regiones cercanas.

- Otra adaptación muy importante fue el cambio en el tipo de vínculos sexuales. De una poligamia que caracteriza a los chimpancés y bonobos, nuestros parientes simios más cercanos, a vínculos sexuales más duraderos "monogámicos" (Chapais, 2008). ${ }^{6}$ Estos vínculos sexuales más duraderos no existen en otros simios y sólo aparece en nuestros antecesores humanos. De acuerdo a Chapais, el cambio a vínculos sexuales más permanentes tuvo efectos muy importantes. Entre otros, permitió a los machos empezar reconocer a sus críos que se mantienen en cercanía con sus madres. Estamos tan acostumbrados a reconocer nuestros familiares que parece difícil de creer que los machos de otras especies de simios no reconocen a sus familiares. Este reconocimiento de sus hijos dentro de nuestros antecesores creó un incentivo para participar en su cuidado y facilitó tener una relación menos agresiva con otros machos que se aparean con sus hijas. Estos "nueros" ya no son vistos como una amenaza a su relación con su pareja. La capacidad de colaborar en metas comunes manteniendo perspectivas y roles diferentes pero complementarias, lo que Tomasello llama una intencionalidad compartida o conjunta (Tomasello et al., 2005) y una capacidad de colaborar en grupos que Tomasello llama una intencionalidad conjunta (Tomasello, 2016). La capacidad de tener prospectivas probablemente se expandió en nuestros antecesores en situaciones que no había la posibilidad de colaborar cara-a-cara y en el "aquí a ahora", y tenían que colaborar a distancia. Cuando nuestros antecesores empezaron a planear una actividad compleja como la caza de grandes mamíferos, los miembros de grupo tenían que tomar roles diferentes. Unos eran rastreadores, otros se escondían en lugares estratégicos para prevenir que la presa no pudiera escapar, unos lanzaban jabalinas y otros creaban una estampida. Esto requirió el poder imaginar diferentes roles y diferentes perspectivas. Para ello fue necesario el desarrollo de capacidad de imaginación y de una memoria capas de visualizar simultáneamente el pasado y el futuro (Suddendorf \& Corballis, 1997). Con ello la capacidad de tomar perspectivas se expandió a un sin número de situaciones y narrativas diferentes, y inclusive a la capacidad de imaginar perspectivas en mundos inventados.

- La importancia del aprendizaje social mediante la imitación y la llamada "sobreimitación" y el aprendizaje basada en prueba y error inventadas por individuos. En la literatura sobre el tema aprendizaje la imitación y sobreimitación se denomina aprendizaje social, y las innovaciones individuales por prueba y error se les denomina aprendizaje asocial. La sobreimitación consiste en imitar gestos o actitudes, aun cuando no tengan utilidad 
inmediata. Por ejemplo, un niño de 304 años ve a un adulto tocar su cabeza antes de enseñarles cómo abrir una caja con juguetes atractivos. Los niños imitan el tocarse la cabeza y después abren la caja. En experimentos parecidos donde la compensación de abrir la caja es comida (los chimpancés no se interesan por los juguetes) solo emulan el abrir la caja si no ven que el tocar la cabeza con la caja los va ayudar a abrir la caja, Es decir, no "sobreimitan", solo se interesan en resultado final (Laland, 2017; Tomasello, 2016, 2019), Desde un punto de vista utilitario la sobreimitación no tiene sentido, pero desde un punto de vista evolutivo tiene la función importante de promover la identificación con otros. Como lo demuestra Kevin Laland, ambos tipos de aprendizaje fueron esenciales para crear sociedades más complejas y cerebros con complejos, pero sorprendentemente la imitación social parece jugar un papel más importante (Laland, 2017). Esta conclusión sorprendente tiene una consideración muy importante. Resulta que la imitación no es tan ciega en muchas especies, incluyendo la nuestra. Poco a poco se van eliminando imitaciones por procesos de selección natural que no contribuyen a la sobrevivencia.

El crecimiento del tamaño del cerebro y de la corteza neocortical que se ve en mamíferos y en primates está relacionado tanto con sociedades más complejas y capacidad de transmitir conocimiento usando la imitación social. Los humanos pudimos crear sociedades transmitiendo este conocimiento de una generación a otra gracias a esta transmisión del conocimiento, Con ello empezamos a crear nuestros propios nichos ambientales en que vivimos, pero a diferencia de otras especies somos el único la única especie en que este nicho ambiental está basado en nuestras capacidades simbólicas y de lenguaje y son culturales.

Otra forma de aprendizaje social que fue esencial para transmitir conocimientos a través de las generaciones es la enseñanza deliberada o pedagogía, en donde un miembro de la especie enseña a otro algo muy específico como el crear herramientas de piedra o aprender cocinar (J. Henrich, 2016; Laland, 2017; Meltzoff, 2005; Meltzoff \& Gopnik, 1993; Sterelny, 2012; Tomasello, 2016).. Estas tecnologías toman tiempo aprenderlas. Otros ejemplos fueron como rastrear $y$ cazar animales, como extraer y encontrar alimentos, como hacer una fogata. Con la excepción de los cuervos, la enseñanza pedagógica es exclusiva de nuestra especie.

- La emergencia de normas sociales y la importancia del prestigio y reputación social. Las normas sociales compartidas permitieron a pequeños grupos de cazadores y recolectores nómades el cooperar en múltiples tareas, adaptando normas tanto convencionales como morales (Boehm, 2012; Leimar \& Hammerstein, 2001; Tomasello, 2014, 2019). Una identidad basada en normas sociales entre miembros que no están limitadas a relaciones cosanguíneas, permitió durante la filogenia de nuestra especie que miembros nuevos pudieran integrarse al grupo aun sin tener otros miembros de su familia en el grupo. Esta en una de las muchas expresiones de la flexibilidad adaptativa de nuestra especie (Gintis, 2003; J. Henrich, 2016; Tomasello, 2016).. 
- Como mencione anteriormente, una desarrollo ontogenético muy diferente de otras especies de primates con la inserción de dos fases nuevas una niñez prolongada y una adolescencia que nos hicieron una especie con vidas muy largas (Bjorklund \& Rosenberg, 2005; Gibbons, 2008)

A continuación, esquematizo esta transformación emocional, relacional, socio-cognitiva y normativa de nuestra especie

\section{Modernidad emocional de nuestra especie}

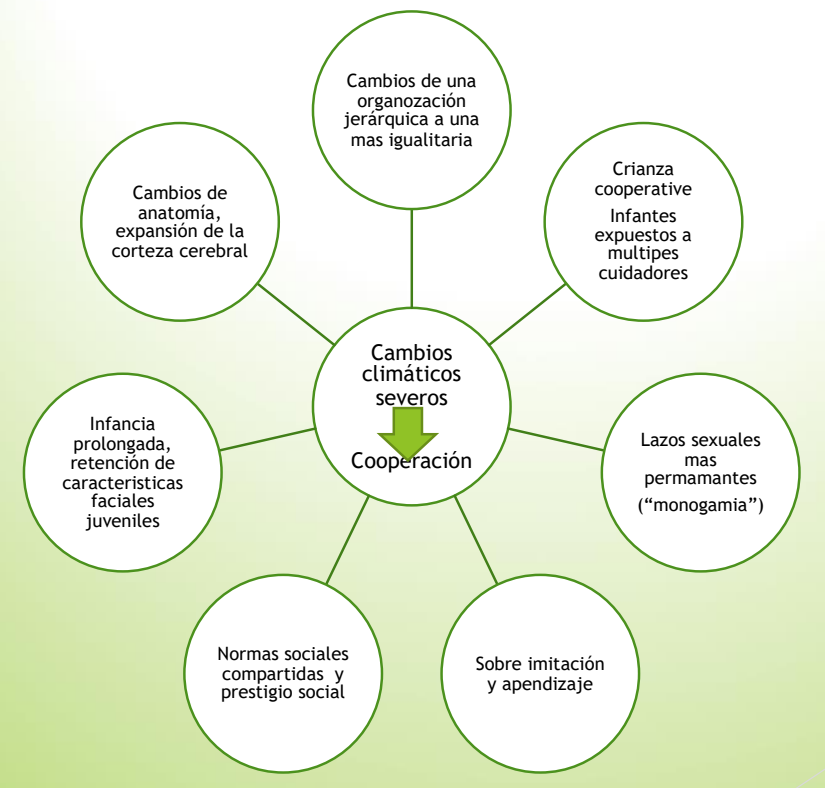

\section{Fase sociocognitiva simbólica y lingüística}

Los cambios en la estructura emocional socio-cognitiva y normativa de nuestra especie preparan el camino para una segunda transformación de nuestros antecesores humanos. En la literatura sobe la evolución humana hay dos términos para describir esta transformación, la modernidad anatómica y la modernidad cognitiva y de conducta. La modernidad anatómica se refiere a la aparición de los primeros fósiles de nuestra especie Homo sapiens. El fósil más antiguo de un Homo sapiens se descubrió recientemente en Marruecos con una fecha de aproximadamente 300,000 años (Gibbons, 2017). A excepción de una bóveda craneana más alongada, este fósil seria anatómicamente indistinguible de un representante humano contemporáneo.

La modernidad conductual se refiere a la aparición arqueológica de una serie de características que incluyen: 
- El uso de símbolos avanzados como el arte figurativo que aparece un Europa en cuevas, y figuras pequeñas de hueso (como las "Venus") y piedras tallados finamente como las puntas de flechas.

- El uso de pigmentos como el ocre rojo para decorar el cuerpo y el uso de joyas y collares.

- El entierro de los muertos.

- Instrumentos musicales.

- Herramientas sofisticadas para cazar y redes para pescar.

- Evidencia de intercambios y trueques hechos a larga distancia.

La modernidad conductual aparece en forma más desarrollada en Europa hace unos 40,000 años, como puede observarse en cuevas de Lascaux y Chauvet en el sur de Francia. Pero elementos de la modernidad conductual aparecen mucho más temprano en forma dispersa en por toda África hace más de 100,000 años o más en forma de collares hechos de concha de mar, el uso del ocre para pintarse el cuerpo, el enteramiento de los muertos o otros artefactos simbólicos (McBrearty, 2007; McBrearty \& Brooks, 2000).

El uso del fuego para cocinar y establecer campamentos para proteger contra predadores se remonta a 400,000 años o más, años (Wrangham, 2009). Las fogatas crean la posibilidad de tener una dieta más variada y la capacidad de digerir más fácilmente la carne y legumbres cocinadas con lumbre. El uso del fuego tiene otros efectos importantes. Favorece la selección de dientes e intestinos más pequeños (Aiello \& Wheeler, 1995). A energía necesaria para masticar $U$ diferir alimentos y una dieta más rica duplica el tamaño del cerebro entre 1200 y $1400 \mathrm{cc}$, en comparación con un antecesor previo, el Homo habilis. Este tamaño es equivalente al tamaño del cerebro de Homo sapiens contemporáneos.

El uso del fuego y un cerebro mucho más grande y complejo llevan a la creación de una tecnología de piedra muy avanzada que permite, entre otras cosas, el usar lanzas con puntas muy finas para cazar animales a distancia. Seguramente las fogatas nocturnas también favorecieron una mayor sociabilidad en una atmosfera relajada e intercambio de información importante para planear la caza y ubicar otras fuentes de comida (Wrangham, 2009). Durante esta fase de la evolución aparecen varios antecesores humanos. Entre los más importantes está el Homo Heidelbergensis que muchos consideran un antecesor común de los Neandertales, otra especie muy cercana a los Neandertales, los Denisovanes, y los primeros representantes primitivos de Homo sapiens.

Nadie sabe cuándo aparece el lenguaje con su estructura sintáctica y generativa extraordinaria, pero en los últimos años han aparecido varias propuestas que ven la aparición del lenguaje como un caso especial de la acumulación fidedigna del conocimiento cultural de una generación a otra. 
Esta acumulación de conocimiento y complexidad creciente de grupos humanos requerida para cooperar en tareas conjuntas, como la caza mayor de animales, creo presiones selectivas pare el desarrollo de comunicaciones más complejos (Sterelny, 2016; Tomasello, 2014). Tomasello propone dos fases en la emergencia del lenguaje. La primera está caracterizada por un sistema rico en imitación de gestos emociones $u$ expresiones vocales (mimesis), y la segunda caracterizada por la emergencia de lenguaje con una gramática y lexicón complejo. La primera fase corresponde a la capacidad de niños de dos años de edad de cooperar con sus cuidadores hacia metas comunes y poder tomar perspectivas del otro, es decir, la intencionalidad conjunta de Tomasello. La segunda fase corresponde a la capacidad de niños mayores de tres años de edad de cooperar en actividades grupales con el soporte de normas sociales que apoyan la cooperación grupas, lo que Tomasello llama una intencionalidad colectiva.

Como Tomasello, Sterelny también propone que la emergencia del lenguaje emerge en dos fases, una mimética y la segunda como sistemas gramaticales y lexicales ricos desarrollados por un largo proceso de convenciones sociales basada en la transmisión cultural del conocimiento. Sterelny agrega una idea muy original. Propone que la estructura gramatical del lenguaje tal vez esté basada en la apropiación de los acoplamientos y refinamientos sensorio-motores que se fueron creando con la manufacturación de herramientas de piedra. Aprender a tallar estas piedras y huesos se requiere mucho tiempo en aprender y es necesario dividir su manufactura en varias secuencias coordinadas. Esta estructura sensorio-motora sirvió como una plataforma para construir la estructura sintáctica del lenguaje. Sea cual fuese el origen de la estructura interna del lenguaje, esta estructura opero dentro del contexto de la infraestructura cooperativa de nuestra especie. Como lo indique anteriormente esta infraestructura incluye la cooperación en la caza y recolección de alimentos, un sistema de crianza cooperativa de los infantes y niños una mayor complejidad social e intercambio con tribus de cazadores y recolectores normados. Todos estos incrementos en complejidad social crearon presiones selectivas fuertes en desarrollar sistema de comunicación más eficaces y eficientes que ya no estaban limitadas a comunicaciones miméticas en el aquí y el ahora. Con el lenguaje emerge un sistema comunicación que integra simultáneamente aprendizajes del pasado, las condiciones cambiantes del presente, y la anticipación de eventos del futuro. Con su incorporación de símbolos y la capacidad de concebir, imaginar y tener múltiples perspectivas del presente, pasado y futuro, el lenguaje funciona como un vehículo comunicativo extraordinario que nos permite crear una infinitud de narrativas que dan significado a las interacciones humanas y a nuestra relación con el mundo que habitamos.

A continuación, esquematizo los elementos que caracterizan la transformación cognitiva y conductiva de nuestra especie. 


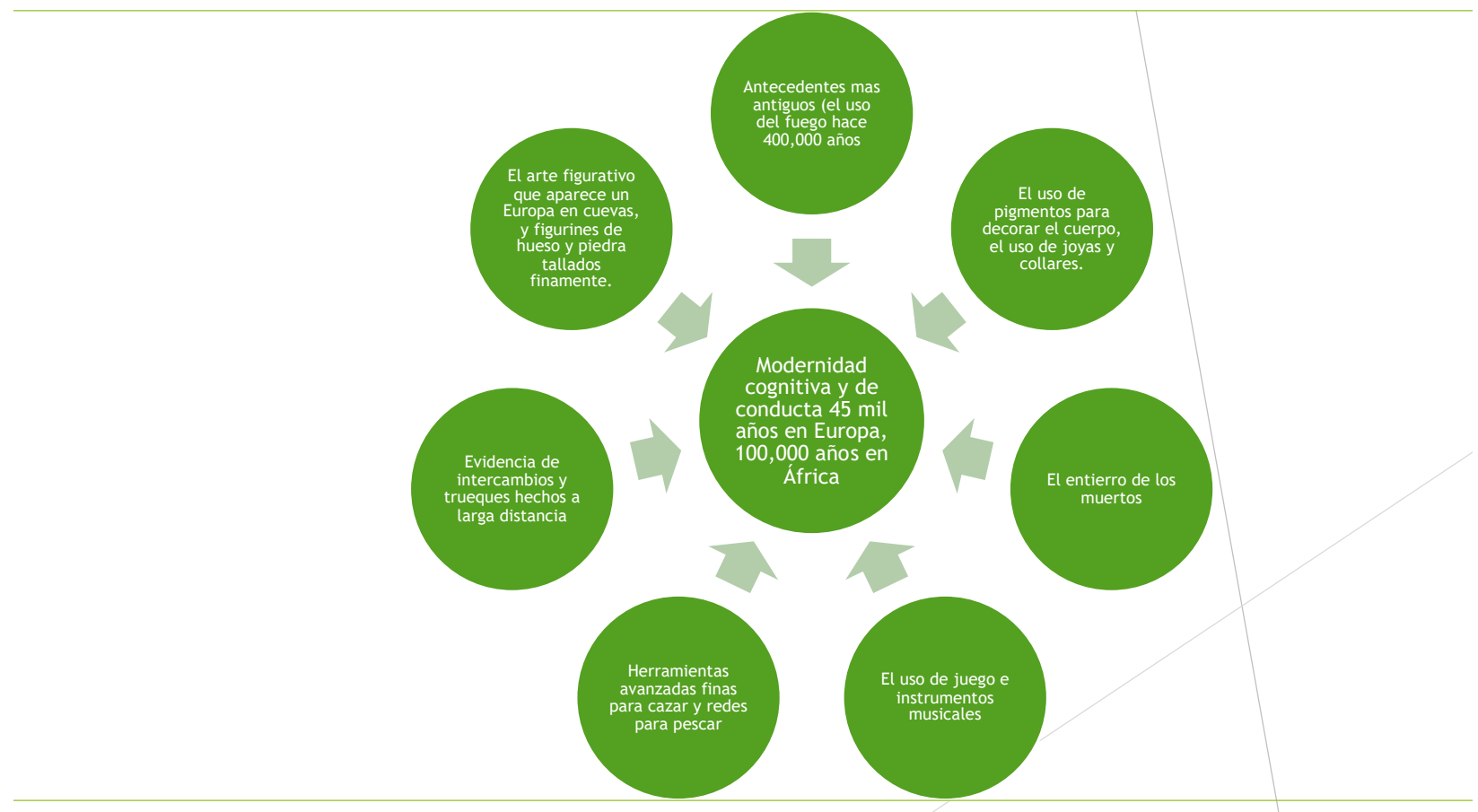

\section{La ontogenia de una mente cooperativa, comunicativa y compartida}

Los diferentes aspectos de la mente cooperativa y compartida de nuestra especie se manifiestan en la ontogenia temprana de nuestra especie y continúan desarrollándose a través de toda la vida. Para fines de exposición en la siguiente tabla separo tres componentes relacionales/emocionales, sociocognitivas y normativas de la mente cooperativa y compartida que están entrelazadas durante el desarrollo:

Componentes de la mente cooperativa y compartida

\section{Relacionales/emocionales Capacidades sociocognitivas Capacidades normativas}

\begin{tabular}{|l|l|l|}
\hline Los sistemas de apego y de cuidado & $\begin{array}{l}\text { Apegos seguros-confianza básica } \\
\text { en la exploración del mundo social } \\
\text { y material }\end{array}$ & \\
\hline $\begin{array}{l}\text { El sistema de enlace social (el } \\
\text { deseo de comunicar y compartir } \\
\text { experiencias en común) }\end{array}$ & $\begin{array}{l}\text { La sonrisa social y las } \\
\text { "protoconversaciones", } \\
\text { capacidades típicas de la } \\
\text { intersubjetividad primaria }\end{array}$ & $\begin{array}{l}\text { Atención conjunta. El gesto de } \\
\text { apuntar (9 meses de edad) -para } \\
\text { compartir experiencias en común- } \\
\text { marca el comienzo de la } \\
\text { Intersubjetividad secundaria. }\end{array}$ \\
\hline validado como personas
\end{tabular}

\section{CeIR Vol. 14 (1) - Abril 2020 ISSN 1988-2939-www.ceir.info}

@ ( Derechos reservados/Copyright de Clínica e investigación Relacional y los autores. Prohibida la reproducción total o parcial sin autorización expresa. Este material es para uso científico y profesional exclusivamente y puede contener información clínica sensible. Los editores no se responsabilizan de los contenidos de los autores. Dirigir las consultas sobre derechos y autorizaciones a ceir@psicoterapiarelacional.es 


\begin{tabular}{|c|c|c|}
\hline $\begin{array}{l}\text { Expresiones de ayudar a otros a } \\
\text { partir de } 14 \text { a } 16 \text { meses de edad }\end{array}$ & $\begin{array}{l}\text { Preferencia marcada de los } \\
\text { infantes y niños a figuras que } \\
\text { ayudan a otros y rechazo a figuras } \\
\text { que no ayudan }\end{array}$ & \\
\hline Afiliación a grupos & $\begin{array}{l}\text { Intencionalidad colectiva o grupal } \\
\text { a partir del tercero a quinto año de } \\
\text { edad (coordinación de metas en } \\
\text { común en grupos) }\end{array}$ & $\begin{array}{l}\text { La emergencia de normas sociales } \\
\text { a partir del tercer año de edad y } \\
\text { sus efectos poderosos de crear } \\
\text { adherencia a valores culturales } \\
\text { compartidos }\end{array}$ \\
\hline \multirow[t]{4}{*}{ Afiliación a grupos } & $\begin{array}{l}\text { La intencionalidad conjunta y } \\
\text { colectiva están ligadas con la toma } \\
\text { de perspectivas o mentalizacion- } \\
\text { ver un misma situación desde mas } \\
\text { de una perspectiva). Esto incluye la } \\
\text { auto-reflexión-tener una } \\
\text { perspectiva de uno mismo-y la } \\
\text { empatía que depende de tener una } \\
\text { perspectiva del otro } \\
\text { (intersubjetividad terciaria ) }\end{array}$ & \\
\hline & $\begin{array}{l}\text { Aprendizaje por medio de la } \\
\text { imitación y sobreimitación y } \\
\text { aprendizaje individual basado en } \\
\text { pruebas y error }\end{array}$ & \\
\hline & Capacidades pedagógicas & \\
\hline & $\begin{array}{l}\text { Capacidades simbólicas, la } \\
\text { imaginación y el lenguaje }\end{array}$ & \\
\hline
\end{tabular}

\section{Componentes relacionales /emocionales}

\section{Los vínculos de apego}

Cualquier descripción de la mente humana tiene que incluir la enorme importancia que juegan los vínculos de apego con sus dos componentes motivacionales complementarios: el deseo de los infantes de ser protegidos y consolados por sus figuras de apego, y el deseo de las figuras de apego de proveer cuidado y consuelo. Como lo enfatizo Bowlby, la importancia de los vínculos de apego no están limitados a la infancia y operan "de la cuna a la tumba" (Bowlby, 1979).

La importancia que tiene el crear vínculos de apego seguros durante el desarrollo son múltiples. Primero, crean una base de confianza básica sabiendo que cuando estamos asustados o afligidos las figuras de apego con las cuales nos vinculamos van a estar disponibles cuando las necesitemos. Segundo, crean confianza de que somos valiosos y queribles. Tercero, nos permiten explorar el mundo social y material con la confianza de que tenemos una refugio y base segura con nuestras figuras de apego. Cuarto, si todo va bien en el desarrollo posterior, se puede 
generalizar esta confianza básica hacia otras figuras importantes como maestras o en relaciones románticas como veremos después. La confianza básica es uno de los elementos más importantes en poder crear cooperación a nivel social. Pero para ello se requiere también que otras personas e instituciones sociales también sean confiables. Aun cuando tengamos una historia de apego seguro, si vivimos en sociedades disfuncionales o violentas la confianza social se derrumba y la cooperación se hace difícil o imposible. Los vínculos de apego tienen que insertarse desde un panorama más amplio de una mente cooperativa y compartida Dentro de este contexto más amplio es notorio el deseo de los infantes de compartir y comunicar experiencias. Este deseo no la busca de protección de figuras de apego, sino que es una expresión de una sociabilidad intersubjetiva primaria más amplia de nuestra especie (Cortina, 2017, 2018b). ${ }^{7}$

Una sociabilidad intersubjetiva primaria: el deseo y capacidad de compartir emociones y comunicaciones durante los primeros nueve meses de edad.

La primera manifestación de la sociabilidad primaria de los infantes es la sonrisa social. La sonrisa social es un catalizador temprano potente del desarrollo socioemocional, y tiene un efecto inmediato de deleite por parte de las figuras de apego y en la gran mayoría de personas que la observan. La sonrisa social es precedida por una sonrisa que se ve cuando lo infantes duermen que aparece durante las primeras 405 semanas de edad. La sonrisa social aparece inmediatamente después y se va desarrollándose gradualmente. Unos 405 meses después los infantes no solo sonríen, sino que se ríen a carcajadas cuando algo los sorprende gratamente o los deleita (L. A. Sroufe, 1996). La sonrisa social es la expresión más temprana del poder expresar y compartir emociones, lo que llama Oren Bader denomina una capacidad de compartir emociones primarias "primary emocional sharing" (Bader, 2020). Esta capacidad "primaria" no debe interpretarse como si las emociones aparecen de repente. Como todo, la sonrisa social tiene su desarrollo propio (L. A. Sroufe, 1996). Las emociones como el júbilo, solo se vuelven intencionales por parte de los infantes al final del primer año de edad cuando lo bebes empiezan a "bromear " con sus cuidadores o apuntar hacia objetos de interés. Un ejemplo de bromear es cuando infantes fingen que les van a dar un objeto al su cuidador solo para retirarlo cuando el cuidador hace el gesto de agarrarlo. El juego se acompaña de grandes carcajadas (Reddy, 2008).

Otra expresión del deseo de compartir emociones y gestos ocurre a los 304 meses de edad con la aparición delas llamadas proto-conversaciones que consisten en una interacción entre los bebes y sus madres que toman turnos en intercambiar balbuceos, gestos, y sonrisas (Bateson, 1971; Beebe, Rustin, Sorter, \& Knoblauch, 2003; Stern, 1985; Trevarthen, 1977; Tronick, 2007). Estas interacciones encantadoras dependen de que los infantes hayan dormido bien, no tengan 
hambre o estén enfermos y estén un estado de alerta. Es decir que estén fisiológicamente regulados.

Tronick y sus grupo hicieron un experimento en que se instruye a las madres que después de interactuar con sus bebes dejaran de interactuar súbitamente con ellos poniendo una expresión inanimada e impasible en su cara (llamado el experimento del "still-face"). Después de aparecer desorientados, los bebes tratan re-conectar a sus madres en la interacción social. Después de varios intentos fallidos se desaniman y caen en un estado de abatimiento retrayéndose en si mismos del que se recuperan cuando sus madres reinician la interacción social. (Tronick, Als, Adamson, Wise, \& Brazelton, 1978). El experimento demuestra lo potente que es el deseo y las expectativas de los bebes de interactuar con sus cuidadores, y lo abatidos que se ponen cuando sus cuidadores no responden a estos deseos y expectativas. Este experimento es la expresión más temprana de la necesidad de ser reconocido y validado por nuestros semejantes. El deseo de ser reconocido y validado es implícito y automático por parte de los infantes. Solo mucho después durante la época escolar y la adolescencia se vuelve plenamente explicito. Mas aun, como lo ha señalado Jessica Benjamin, esta necesidad de reconocimiento tiene que convertirse en un reconocimiento mutuo para que haya un desarrollo integral (Benjamin, 1992, 2004). El reconocimiento mutuo es también una de las bases fundamentales para la convivencia y el bienestar humano. Lewis Aron ha enfatizado lo importante que es esta dimensión de mutualidad en la relación de paciente con su analista (Aron, 1996). Este mundo intersubjetivo que se va volviendo socialmente más complejo con variaciones culturales importantes. Un ejemplo de estas variaciones lo ha documentado Colwyn Trevarthen y sus colaboradores en los suburbios de la cuidad de Lagos en Nigeria. En Nigeria las interacciones de las madres con sus bebes están más basadas en el tacto, que en las poblaciones de clase media de Escocia y Estados Unidos, donde las interacciones son más verbales (Trevarthen, 1988).

Hay dos polos de este desarrollo socio-emocional del niño. Un polo donde los infantes desde muy temprano muestran una capacidad de agencia como cuando mueven accidentalmente un objeto y empiezan a repetir la acción. Poco a poco van aprendiendo que pueden causar cambios en su mundo y van descubriendo la causalidad de sus acciones. Este es el polo de un "yo" interactuando con el mundo y pudiendo modificarlo. El otro polo es el del "tú y yo" haciendo algo juntos creando un "nosotros" que se inicia con la sonrisa social y continua con las protoconversaciones. Es importante mencionar que todas estas interacciones son diádicas.

Para finales del primer año de edad las interacciones se vuelven tríadicas. La expresión prototípica de esta atención conjunta tríadica es el apuntar con el dedo índice a objetos o eventos de interés, y el mirar juntos hacia un objeto de interés común. Los infantes empiezan a tomar un papel activo en compartir con sus cuidadores si interés en objetos y eventos del mundo que los 
rodea. Estas expresiones tríadicas es lo que lo que denomina como atención conjunta (Gallagher, 2011). La atención en interacciones diádicas como en las proto-conversaciones preparan a los infantes para interacciones tríadicas a partir de los 9 a 12 meses de edad.

Hay discrepancias entre diferentes autores en definir en que consiste la atención conjunta tríadica que empieza poco después. De acuerdo a Melinda Carpenter y Josep Call la controversia en gran parte se debe a diferentes definiciones a lo que se refiere "conjunto" en la atención conjunta (Carpenter \& Call, 2013). La definición con que todos concuerdan define atención conjunta como una relación tríadica en la que dos individuos que coordinan su atención hacia un mismo objeto. Esta definición ha gravitado en direcciones divergentes. Algunos investigadores se han enfocado en la conducta de dos individuos observando el mismo objeto, pero para otro grupo de investigadores la conducta no es suficiente, es necesario enfocarse también en la calidad de esa atención conjunta. Pare este segundo grupo la calidad consiste en un saber juntos, y no solo el apuntar como un gesto informativo.

Un grupo de investigadores compuesto de primatólogos se enfocan en la conducta lo para enfatizar las muchas semejanzas que existen entre nuestros parientes mas cercanos los chimpancés y bonobos (Bard et al., 2005). Piensan que hay un prejuicio entre los psicólogos de querer usar características, como la atención conjunta, como un fenómeno exclusivamente humano. Y en efecto, si solo nos enfocamos en la conducta tienen razón. Chimpancés y bonobos criados por humanos también aprenden a apuntar. Aducen estos investigadores de que si los bonobos son criados por humanos y aprenden a apuntar, no hay manera de distinguir entre las especies. Pero el grupo de investigadores que se enfocan en la calidad aun en este caso se ven diferencias entre los chimpancés y bonobos y los humanos. Melinda Carpenter y Kristin Liebal demuestran que pueden distinguir en forma confiable entre miradas en que el objetivo es comunicativo, y las miradas que tienen tiene la calidad de un saber algo juntos (Carpenter \& Liebal, 2011). Si los infantes pudieran poner en palabras de este "saber algo juntos" dirían "yo se que tu sabes que estamos disfrutando este objeto que nos interesa a los dos". Este saber algo juntos tiene un tono afectivo que puede variar desde deleite, interés/curiosidad o inclusive disgusto.

Este tipo de atención conjunta ("yo se que tú sabes") es lo que también se designa como un pensamiento referencial, y lo que en círculos académicos se designa como "teoría de la mente". Es también lo que Fonagy y sus colaboradores consideran el principio de la capacidad de mentalizacion. El poder mentalizar implica el poder ver una situación desde perspectivas diferentes (ver la sección sobre perspectivas donde abordo el tema). Melinda Carpenter y Josep Call han hecho una distinción similar entre atención conjunta con miradas que tiene la función 
de compartir y saber algo juntos, y miradas que tiene la función de solicitar objetos (Carpenter \& Call, 2009, 2013).

Otro equipo de investigadores que llega a conclusiones similares son Robert y Jessica Hobson. Con una metodología diferente, los Hobson han podido distinguir entre miradas cuyo objetivo es "checar" o "orientar" y moradas cuyo objetivo es compartir algo juntos ("miradas compartidas)". Las miradas cuyo objetivo es checar no requieren una sincronización afectiva como las miradas compartidas. Los Hobson han usado dos criterios, con buen acuerdo entre evaluadores, para distinguir entre miradas de checar (orientadoras) y miradas compartidas. En contraste con miradas de checar, las miradas compartidas tienen profundidad (el ver dentro del ojo del otro en vez de hacia el otro), y reciprocidad, el ver que el otro también está mirando y manteniendo contacto afectivo. Los Hobson también han demostrado que estas diferencias cualitativas distinguen infantes con un desarrollo típico o normal-que tienen el deseo de compartir experiencias con adultos-y el desarrollo de niños autistas cuya atención conjunta tiene una función de checar y orientación con otros, y no de compartir experiencias con tonos afectivos (R.P. Hobson \& Hobson, 2011).

Vistas en conjunto, estas distinciones y experimentos apoyan la tesis de que tenemos una mente diseñada para compartir experiencias y buscar compañía con otros. A la pregunta de qué es lo que nos hizo humanos Melina Carpenter y Joseph Call concluyen diciendo que "nosotros pensamos que la respuesta a la pregunta es que sólo los humanos han evolucionado en la motivación básica de compartir y alinear estados psicológicos con otros". (Carpenter \& Call, 2013, p.58).

Como veremos en las siguientes secciones, los méritos de esta hipótesis es que provee una explicación unificada de lo que separa a los humanos de nuestros parientes cercanos simios, en una plétora de capacidades socio-cognitivas: las proto-comunicaciones o comunicaciones cara a cara descritas anteriormente, la atención conjunta, la imitación, la toma de perspectiva y las capacidades de aprendizaje. Todas estas capacidades requieren de la capacidad de alinear estados psicológicos y emocionales con nuestros semejantes.

Pero no es solo la motivación de querer compartir y alinear estados psicológicos lo que nos hizo humanos. El proveer cuidado y prestar ayudad se extendió con la crianza colectiva a miembros de nuestro grupo cercano y esta motivación de ayudar a otros se manifiesta en niños de 16 a 18 meses de edad apenas. 


\section{Ayudando a extraños}

Tómaselo y sus equipo de colaboradores demuestra que infantes de 16 a 18 meses de edad espontáneamente ayudan a extraños (Warneken \& Tomasello, 2007). Por ejemplo, un extraño tiene sus manos llenas de libros y trata de abrir la puerta de un gabinete. Sin que sus madres lo instiguen, estos niños pequeños abren la puerta espontáneamente. En otro experimento el extraño se le cae algo de la mano accidentalmente que no puede alcanzar y los niños inmediatamente lo recogen. Como control, los investigadores hicieron experimentos similares donde era obvio que el extraño no necesita ayuda. En estos casos los niños no tratan de ayudar. Para demostrar que este gesto espontaneo de ayuda es intrínseco y no depende de la aprobación o premio de sus madres, los investigadores premian con un juguete a los niños que ayudan espontáneamente. Encontraron que el deseo de ayuda disminuye rápidamente en comparación con niños que no recibieron un premio (Warneken \& Tomasello, 2008). Otros experimentos demuestran que la presencia o falta de presencia de los padres no modifican estos gestos de ayuda. Es más, niños de 203 años de edad ayudan a extraños aun con un costo personal para ellos mismos (Svetolova, Nichols, \& Bronwell, 2010).

Una de las pruebas más convincentes de la prosociabilidad de los niños es usando la dilatación pupila que refleja el estado de estimulación o relajación del sistema nervioso autonómico o periférico (SNA). Cuando hay tensión las pupilas dilatadas indica que el SNA está estimulado, si hay contracción pupilar el SNA está relajado. Una serie de experimentos por el equipo de Tomasello demuestran hecha que las pupilas de los niños se mantienen dilatadas si alguien necesita ayuda y se contraen cuando ellos, o otros, proveen la ayuda (Hepach, Vaish, \& Tomasello, 2012, 2013). Esa es otra prueba de que su deseo de ayudar es intrínseco y no depende de si los niños son premiados que sería una motivación extrínseca.

Otra expresión de esta tendencia a ayudar es la preferencia marcada que muestran los infantes desde edad muy temprana a favorecer a figuras o títeres que ayudan y su desaprobación cuando estos títeres obstaculizan la ayuda (Hamlin \& Wynn, 2011; Hamlin, Wynn, \& Blomm, 2010).

Estos gestos de ayuda no son exclusivos de nuestra especie (Warneken, Hare, Melis, Hanus, \& Tomasello, 2007; Warneken \& Tomasello, 2007). Los chimpancés, por ejemplo, ayudan espontáneamente pero solo cuando el costo de es alto. Si se trate de un recurso preciado, como la comida, los chimpancés no la comparten aun cuando sea obvio que hay más comida fácilmente disponible (Warneken \& Tomasello, 2009). 
Capacidades socio-cognitivas: la Intencionalidad conjunta

Otra expresión importante en el desarrollo de la mente compartida es la capacidad de niños pequeñas de coordinar sus intenciones con adultos en metas en comunes (Tomasello et al., 2005). Estas interacciones son una expresión más avanzada de un "nosotros" haciendo algo juntos. En comparación con las interacciones diádicas que crean un nosotros durante los primeros 9 meses de edad, este "nosotros" más avanzado está enfocado en el mundo exterior. La colaboración de nuestros parientes más cercanos, los chimpancés, es diferente. Colaboran en forma individualista y en la medida que ve una ganancia personal, y no como un "nosotros". (Jensen, Call, \& Tomasello, 2007).

\section{La capacidad de tener perspectivas múltiples}

La intencionalidad conjunta tiene una estructura dual individual y social: cada persona conserva una perspectiva individual en labores colaborativas y a la vez colabora socialmente poniéndose en el lugar del otro en labores colaborativas (Tomasello et al., 2005). Una demostración muy clara de esta estructura dual individual y social se ven en que los infantes de 18 meses de edad pueden cambiar roles con adultos en actividades conjuntas. Esto significa que pueden tomar la perspectiva del adulto sin perder de vista la suya propia. En cambio, los chimpancés no pueden cambiar de roles en actividades donde colaboran con otros y tomar la perspectiva del otro. Por lo tanto, sus capacidades de colaboración son mucho más limitadas (Carpenter \& Call, 2013).

Como todo, la toma de perspectiva tiene un desarrollo gradual. Al principio está limitado a interacciones diádicas donde los infantes pueden tomar la perspectiva del otro cuando están colaborando hacia metas comunes cara-a-cara. En los niños pequeños se puede ver este desarrollo de la toma de perspectivas cuando empiezan usar su imaginación y lenguaje (Carpenter, Tomasello, \& Striano, 2005; Decety, 2005; Meltzoff \& Gopnik, 1993; Miller, 2007; Mohl \& Tomasello, 2007; Moll \& Meltzoff, 2011; Onishi \& Baillargeon, 2005). El tema del desarrollo de la toma de perspectivas es complejo y difícil resumir y está ligada a capacidades como como la autorreflexión, la mentalizacion, la empatía, y lo que en círculos académico se denomina "teoría de la mente". La autorreflexión consiste en poder tener una perspectiva de uno mismo en interacciones con otros. La mentalización es definida de varias maneras, pero su esencia es el poder ver en otros y en uno mismo estados mentales y psicológicos, y está intimamente ligada a la autorreflexión. Otro concepto afín es lo que en círculos académicos se llama "teoría de la mente" (Meltzoff, 1999; Perner, Ruffman, \& Leekam, 1994; Wellman, Cross, \& Watson, 2001). El tener una teoría de mente es el poder concebir a otros estados mentales como creencias e intenciones en otros (y en uno mismo). La empatía consiste intuir en otros lo que otros piensan y sienten y también está íntimamente ligado con la capacidad de toma de 
perspectivas (Decety, 2005). Quiero nuevamente enfatizar que la capacidad de tener perspectivas múltiples no sería posible sin el desarrollo previo del deseo de compartir experiencias intersubjetivas durante el primer y segundo año de edad y el poder identificarnos con nuestros semejantes.

El aprendizaje social por medio de la imitación, sobreimitación e innovaciones basadas en la prueba yerror

La capacidad de imitación y copiar empieza a partir del segundo año de edad y sique vigente durante el transcurso de la vida. La sobreimitación que consiste en imitar gestos que no tiene un fin utilitario tiene su apogeo a los 4 a 5 años de edad. Nunca desaparece del todo y aparece en forma inconsciente en múltiples interacciones sociales tanto en niños como en adultos. Varios autores consideran este tipo de imitación como uno de los factores más importantes que nos permite nos permite inconscientemente identificarnos con nuestros semejantes. Andrew Meltzoff considera "el ser perecido a mi" (the "like me" hipótesis) como una fundación de la cognición social (Meltzoff, 2007).

Los Hobson también piensan que la imitación inconsciente es esencial en el poder identificarnos con otros. Demuestran que esta capacidad de imitación de gestos y actitudes inconscientes que ocurre en niños con desarrollos típicos, no ocurre en niños autistas (R. P. Hobson, 2004; R.P. Hobson \& Hobson, 2011). Esta es otra indicación de que el poder identificarnos con otros es una capacidad de vinculación fundamental en nuestra especie, y cuando esta no ocurre en forma apropiada, como en niños autistas, tiene efectos devastadores para el desarrollo.

De acuerdo con Victorio Gallese, esta capacidad de imitar e identificarnos con los demás tiene una base neuronal. El descubrimiento de neuronas espejo que permite que automáticamente podamos simulan, a nivel neuronal, las acciones en los demás (Rizzolatti, Fadiga, Gallese, \& Fogassi, 1996). Gallese piensa que este sistema de simulación neuronal se expandió para incluir la simulación de gestos y emociones, lo que Gallese llama la matriz múltiple interpersonal o intersubjetica de nuestra mente (Gallese, 2002).

\section{Capacidades pedagógicas}

Una de las conclusiones más importantes que emergen de modelos matemáticos que simulan procesos evolutivos comparando diferentes maneras de aprendizaje es que la enseñanza en que un instructor enseña a otro (a un costo grande pare el instructor o maestro) tuvo un efecto enorme en la capacidad de transmitir conocimiento atreves de las generaciones en forma eficiente y fidedigna (Laland, 2017)., Laland piensa que este tipo de instrucción es parte de un 
paquete más amplio de capacidades sociocognitivas y de lenguaje que nos hizo seres culturales, culturas que nosotros mismos creamos.

En lo que llaman una "pedagogía natural", Csibra y Gergely proponen que la comunicación human está diseñada pare transmitir conocimiento entre individuos, y que los infantes humanos esta preparados pare recibir e interpretar esta comunicación aun sin entender el lenguaje (Csibra \& Gergely, 2009). Por otra parte, Kim Sterelny propone una forma de aprendizaje basado en un sistema de "aprendiz" donde el alumno aprende de un experto por un largo proceso de observación. El prototipo de este sistema de "aprendiz" y alumno de gran importancia para nuestros antecesores, fue aprender a como tallar piedras para crear herramientas (Sterelny, 2012). En este proceso la instrucción el lenguaje verbal no es esencial, y más bien depende un largo proceso de aprendizaje sensorio-motor basado en la imitación.

\section{Normas sociales y afiliación a grupos}

Junto con la importancia de las normas sociales compartidas, la afiliación a grupos funciona como un pegamento social que permite que grupos humanos podamos colaborar y ayudarnos mutuamente. La afiliación a grupos probablemente es una extensión de una sociabilidad muy temprana que vemos con la sonrisa social y las proto-conversaciones en los infantes y no un sistema motivacional nuevo. Si es así, seria un ejemplo más de innumerables casos que se dan durante la evolución natural en que muchas adaptaciones previas-en este caso una sociabilidad temprana muy extensa que se desarrolla ripiadamente durante el primer y segundo año de edad-son reusadas o recicladas en contextos nuevos y para fines adaptativos nuevos.

Hay una literatura muy amplia sobre como las normas sociales y valores morales compartidos empiezan a moldear e influir en forma potente en el comportamiento de los niños en sus intenciones con sus pares y con adultos. Hay dos líneas de investigación que muestran esto claramente. La primera line de investigación este basado en estudios de diseño longitudinal y demuestran claramente que el éxito que van a tener los niños prescolares y escolares de colaborara con sus pares y sus maestros depende en gran medida de la calidad de los vínculos de apego que se han establecido previamente (L.A. Sroufe, Carlson, Levy, \& Egeland, 1999; L. A. Sroufe et al., 2005; L. A. Sroufe, Egeland, \& Carlson, 1999). Historias de apego seguro también predicen la capacidad la mayor capacidad de niños prescolares de regularse emocionalmente, de llevarse bien con sus pares y su capacidad de empatía. También predicen una mayor independencia con sus maestros y capacidad de usarlos como un recurso cuando lo necesitan. Historias de apego inseguro, ya sea de tipo resistente o evitativo, demuestran lo contario: una menor capacidad de regularse a si mismos, mayores problemas en llevarse bien con sus pares y menor empatía, sobre todo en casos de historias d apego evitativo. Apegos inseguros también 
predican una mayor dependencia de los niños con sus maestros y menor capacidad de usarlos como recursos.

Una segunda línea de investigación demuestra como a partir del tercer año de edad las normas sociales tienen un efecto profundo en la conducta y adaptación a los grupos culturales en que se están desarrollando los niños. Antes del tercer año de edad los infantes se relacionan principalmente con sus cuidadores primarios y figuras de apego. En la medida en que juegan e interactúan con sus con sus pares, su juego es paralelo y cada quien hace su propia cosa. No hay una verdadera reciprocidad social.

Hay muchos estudios de esta naturaleza, por lo que solo voy a mencionar algunos ejemplos. Estos estudios distinguen entre normas sociales que son arbitrarias y convencionales, como la formas de vestir o de saludarse, y normas sociales que tienen que ver con el bienestar de los demás y con la justicia. Numeroso estudios demuestran que niños prescolares hacen cumplir tanto normas convencionales como normas morales, pero las normas morales tienen más peso (Schmidt \& Tomasello, 2012).

- Los niños prefieren a sus compañeros que hacen cumplir normas sociales que aquellos que no las hacen cumplir (Tomasello, 2016, p. 120)

- Niños pre-escolares, pero no niños menores de 3 años de edad, empiezan a hacer cumplir normas sociales sin que sus maestros les digan nada. Por ejemplo, cuando ingresa un niño nuevo a la escuela le suelen decir "colgamos nuestros abrigos aquí". (Köymen et al., 2014).

- Los niños hacen cumplir normas convencionales para su propio grupo social, pero no para otros grupos a que no pertenecen. Sin embargo, protestan cuando hay violaciones a normas morales como el no pegar a otros niños. Esta norma las ejercen para su grupo y para otros grupos de niños que no pertenecen a su grupo social (Schmidt, Rakocky, \& Tomasello, 2012). Contextualizan normas convencionales y normas sociales en forma diferente. Entienden que otros grupos tiene normas convencionales diferentes, pero universalizan normas morales aun en grupos a los cuales no pertenecen.

- Los niños pequeños 3 a 5 años de edad son bastante dogmáticos en como se deben cumplir las reglas de sus juegos. Pero estudios con niños de 5 a 7 años de edad muestran que se vuelven más flexibles en como cumplir reglas de juego y jugar juntos (Köymen et al., 2014)

- Los niños rápidamente internalizan normas sociales que favorecen su adaptación a grupos (Gintis, 2003; J. Henrich, 2016; Tomasello, 2016). 
La emergencia de capacidades simbólicas y el lenguaje

El desarrollo ontogénico de capacidades simbólicas y de lenguaje es bien conocido. Así como vimos en la filogenia, durante la ontogenia los niños desarrollan sus comunicaciones en dos fases. Una primera fase mimética que consiste en el intercambio de los balbuceos, gestos y emociones y una segunda fase basado en la construcción du una estructura sintaxis y lexicón complejos. A partir del año y medio los infantes empiezan a usar sus primeras palabras y usar símbolos. Un ejemplo común del uso de símbolos es una niña de año y medio de edad que usa una cuchara y hace ruido de un avión, o usa la cuchar para alimentar a su muñeca. Esta capacidad simbólica alcance rápidamente y a los 405 años de edad los juegos de fingir alcanzan se vuelven comunes hasta el grado de que algunas veces los niños no pueden hacer bien la distinción entre el fingir y la fantasía y la realidad—con variaciones culturales muy grandes.

Al final del segundo año de edad, con variaciones culturales y genéticas, el vocabulario de los niños empieza a expandirse y empiezan usar frases pequeñas. Par el tercer a quinto año de edad la estructura lingüística se vuelve rápidamente más compleja y empiezan a expresar pensamientos más complejos que permite ver su mundo desde múltiples perspectivas. Tanto las capacidades simbólicas como la adquisición del lenguaje tienen un desarrollo fuertemente canalizado. Todos los niños con un desarrollo típico can empezar a usar pensamiento simbólico y adquirir un lenguaje.

\section{Comparación con los simios (nuestros parientes primates más cercanos)}

En los últimos 25 años Tomasello y sus colegas han desarrollado un programa de investigación sistemático comparando niños pequeños con los chimpancés y los bonobos. Escogen para su comparación niños menores de tras años de edad para minimizar el impacto enorme de la cultura en que cercen. Estos estudios se basan en la premisa que tuvimos un antecesor común con los chimpancés y bonobos aproximadamente hace 6 millones de años, y compartimos con ellos de un $98 \%$ de genes. Si aparecen motivaciones y capacidades sociocognitivas prosociales semejantes en niños y niñas pequeños y en nuestros parientes más cercanos los chimpancés y bonobos, esto es evidencia de que el antecesor común ya poseía estas motivaciones y capacidades prosociales. Pero si estas adaptaciones prosociales son nuevas o aparcan en forma mas avanzada en infantes y niños en comparación con los chimpancés y bonobos, esto es evidencia que emergieron durante el transcurso de los últimos 6 millones de años.

Para empezar esta comparación voy resumir una de las investigaciones más completas que se han hecho comparando entre niños y niñas pequeños con dos especies de simios, los chimpancés, y los orangutanes (Hermann, Call, Hernández-Lloreda, Hare, \& Tomasello, 2007). 
Los investigadores administraron una serie de pruebas ecológicamente sensibles que comparan capacidades de manejar y entender el mundo material (con problemas que muestran la capacidad de entender relaciones espaciales, de cantidades, de relaciones de causalidad, y el uso de herramientas), con capacidades para manejar y entender el mundo social (como capacidades de imitación, de comunicación, y de entender los gestos y las intenciones de sus congéneres). La muestra consistió en 105 niños y niñas de dos años y medio de edad, 106 chimpancés, y 32 orangutanes. El objetivo del estudio era ver si había diferencias entre estas especies en sus competencias de sus interacciones con el mundo material y social. Los resultados demostraron similitudes entre las tres especies en sus competencias de manejarse con el mundo material, pero encontraron diferencias claras es su manejo el mundo social. Los niños pequeños y los chimpancés tienen aproximadamente las mismas capacidades en su manejo del mundo material-con los orangutanes demostrando ser un poco menos capaces. En cambio, hay diferencias claras en cuanto a capacidades para manejar el mundo social. Los niños pequeños (suficientemente grandes para tener un poco de lenguaje, pero muy lejos aún de ser escolares), muestran capacidades sociocognitivas bastante más sofisticadas para manejar el mundo social.

Una conclusión general de una serie de investigaciones es que los chimpancés entienden perfectamente bien las intenciones y la mente de miembros de su propia especie en situaciones competitivas, pero no en situaciones cooperativas. Para demostrar esto Tomasello y sus colegas han usado varios experimentos. Un experimento consiste en poner un humano y un chimpancé frente a frente con una plataforma de por medio. El humano y el chimpancé estén detrás de barreras transparentes hechas de Plexiglás con un hoyo en medio de la barrera por la cual pueden agarrar cubetas con comida (Hare \& Tomasello, 2004). En la primera parte del experimento el humano está cooperando con el chimpancé señalando con la mano y el dedo extendido dónde está la comida escondida en una de las tres cubetas. Sorprendentemente el chimpancé no entiende el gesto cooperativo de ayuda y escoge al azar. No es que el chimpancé no entienda el gesto del dedo extendido en sí mismo, ya que chimpancés criados en cautiverio usan este gesto para señalar lo que quieren con los humanos. Lo que no entienden es el gesto cooperativo de ayuda En la segunda parte del experimento se cambia de paradigma a uno de competitividad entre el humano y el chimpancé. Se pone una sola cubeta con comida en medio de la plataforma para ver quien la agarra primero. Después de uno o dos ocasiones en que el humano agarra la comida primero, el chimpancé se da cuenta de que el humano está compitiendo por la comida, y en las siguientes rondas trata de agarrar la comida antes de que la agarre el humano. En ambos casos el gesto de cooperar con la mano extendida y de extender la mano para agarra la comida se parecen, pero los chimpancés solo entienden su significado cuando están compitiendo con otros por comida. 
Otro experimento con chimpancés que no involucra humanos demuestra que los chimpancés son perfectamente capaces de imaginarse lo que sus congéneres piensan en situaciones competitivas, pero no así en situaciones cooperativas. En este experimento dos chimpancés con diferente rango jerárquico se encuentran en jaulas separadas que se pueden abrir a un espacie común. En el espacio común ven a un ayudante humano poner comida en una cubeta. En la primera parte del experimento se abren las jaulas y el chimpancé con un rango menor no se atreve a competir con el chimpancé dominante por la comida. En la segunda parte del experimento se pone una barrera opaca en el espacio común, de manera que el chimpancé dominante no puede ver lo que está pasando del otro lado de la barrera opaca que está a la vista del chimpancé con un rango menor. Un ayudante pone comida en la cubeta del lado del chimpancé de rango menor. Viendo que su compañero dominante no puede ver la cubeta, el chimpancé toma la comida sin miedo de ser visto. El chimpancé de menor rango puede imaginarse lo que su congénere dominante no percibe. Tomados en conjunto, estos experimentos demuestran que chimpancés tienen una "teoría de la mente" cuando se trata de situaciones competitivas, pero no en situaciones cooperativas.

A pesar de estos experimentos hay que enfatizar que en observaciones hechas en ambientes naturales se ve que los chimpancés colaboran de diferentes maneras. Por ejemplo, se pueden acicalar mutuamente, pero los compañeros que escogen para ello son para beneficio propiocomo cultivar la buena voluntad de otro miembro miembros de una coalición que está manteniendo la jerarquía social de su grupo. Otro ejemplo, en este caso de cooperación grupal, es el cazar otros primates más pequeños que se encuentran, para su mala fortuna, en su territorio. Pero en esta caza no hay una coordinación de roles distintos como se ven en los cazadores y recolectores nómades humanos, donde los miembros del grupo de cazadores planean estratégicamente la caza y se asignan roles diferentes. Entre los chimpancés cada miembro está motivado por ser el primero en aprehender la presa. En medio de la caza algunos bloquean las rutas de escape de la presa para llegar primero a ella, pero no como un intento de coordinación. Después de que un chimpancé logra capturar su presa, solo comparten la carne a regañadientes y ante la persistencia de los otros miembros del grupo. Esta tendencia a no compartir comida se puede ver inclusive en las madres que sólo comparten comida con su crío que desechan. No alimentan a sus crías como hacen las madres humanas. Los chimpancés aprenden desde muy temprano a valerse por sí mismos.

Solo los humanos desarrollan a partir de los 9 a 12 meses de edad el gesto de apuntar para compartir objetos de interés con los adultos (Liszkowski, Carpenter, Henning, Striano, \& Tomasello, 2004). Los chimpancés en cautiverio aprenden a usar el gesto para solicitar cosas de 
los humanos. Solo una vez en se ha visto este gesto en ambientes naturales (Bullinger, Kaminiski, Zimmerman, \& Tomasello, 2011).

Otro experimento revelador demostró que niños de 2 a 3 años de edad está basado en la premisa de que los adultos crean un compromiso explícito cuando invitan a un niño o niña a participar en un juego. En cambio, en los chimpancés no hay este compromiso explícito. Cuatro juegos diferentes fueron usados que podían ser jugados por un solo jugador o con un compañero. El experimento solo podía iniciarse cuando el niño aceptaba jugar con el adulto (Gräfenhain, Behne, Carpenter, \& Tomasello, 2009). La condición de control consistía en un adulto uniéndose a los juegos sin haber sido invitado a un juego que ya habían iniciado los niños por sí mismos. La característica esencial del experimento consistió en que el adulto suspendía el juego sin dar explicaciones en ambas condiciones. Los niños mayores (pero no los de 2 años) insistieron en que el adulto continuara jugando el juego con el que habían aceptado jugar juntos, pero no insistieron en que el adulto continuara jugando cuando éste se había introducido sin invitación a juegos que los niños habían iniciado por sí mismos. Los chimpancés en experimentos similares no dan ninguna señal de que estén comprometidos a corresponder en labores conjuntas a menos que sea para su beneficio.

En resumen, estos experimentos son un reflejo de que las dos especies han evolucionado bajo presiones selectivas muy diferentes. En los chimpancés los ambientes, tropicales, semitropicales y forestales en que viven no han cambiado sustancialmente en millones de años y su organización jerárquica que predomina en la mayoría de los mamíferos no ha tenido que cambiar. En nuestros antecesores humanos las presiones selectivas operaron en ambientes totalmente diferentes, como la sabana africana, acompañado de cambios climatológicos severos. Estos cambios favorecieron la cooperación en grupos. Pero para que la cooperación fuese tan extensa, tuvo que acompañarse con cambios en motivaciones y capacidades prosociales que se manifiestan como diferencia entre las dos especies (Warneken \& Tomasello, 2006).

\section{Implicaciones del modelo evolutivo y del desarrollo de una mente cooperativa y ultrasocial para psicoanálisis relacional}

La concepción de una mente humana cooperativa motivada para el deseo de vincularse y compartir con otros y con nuestras experiencias propias apoya de una manera contundente la revisión del psicoanálisis propuesto por los pioneros del psicoanálisis relacional. con la cual incluyo psicoterapia psicoanalítica cara-a cara. El psicoanálisis relacional en particular con una perspectiva basada en el desarrollo y la importancia de la relación terapéutica tiene un 
acoplamiento y engranaje con cinco de las dimensiones descritas anteriormente que constituyen la mente cooperativa descritas anteriormente. Mencionare cinco:

1. Una base segura para la exploración.

2. Una relación colaborativa, el ingrediente más importante de la alianza terapéutica.

3. Una relación de mutualidad, reciprocidad, y reconocimiento mutuo donde compartimos nuestra humanidad.

4. Perspectivas nuevas con las cuales podemos entendernos a nosotros mismos y entender nuestras relaciones más importantes. Esta dimensión es referida como capacidad de autorreflexión y mentalización, y lo que tradicionalmente ha sido descrito como insight.

5. Acceso a capacidades simbólicas, de imaginación y de lenguaje.

\section{Crear Una base segura para la exploración}

La expresión más clara de esta dimensión lo proporciona la teoría de apego que ha demostrado contundentemente que el crear un refugio de seguridad y una base de exploración durante el desarrollo temprano tiene efectos que duran de por vida (A. Sroufe, 2016; L. A. Sroufe et al., 2005). Muchos otros analistas han concurrido en la necesidad de crear esta base de seguridad y confianza es una condición vital para el ejercicio de cualquier tipo de psicoterapia relacional. Las investigaciones de apego también han demostrado que el ingrediente mas importante en poder crear una relación de apego con infantes y niños mayores en la sensibilidad de las figuras de apego (Ainsworth et al., 1978). En la literatura psicoanalítica la respuesta sensible ha sido descrita en términos parecidos por Howard Bacal como "una respuesta optima" (Bacal, 1985).

\section{Crear una relación colaborativa, el ingrediente más importante de la alianza terapéutica.}

El modelo de una mente cooperativa y compartida apoya uno de los hallazgos más importantes sobre la investigación sobre la eficacia en diversos escuelas de psicoterapia: la flexibilidad y competencia del terapeuta de crear una alianza terapéutica es uno de los mejores predictores de su eficacia (Levy \& Ablon, 2009; Norcross, 2002). Cada relación terapéutica es singular. El poder crear esta alianza terapéutica que responde a esta singularidad, y poder acoplarse a las personalidades y necesidades de cada paciente depende de la flexibilidad y sensibilidad del terapeuta. La teoría de la especificidad de cada paciente y cada relación terapéutica de Howard Bacal (2006), se enfoca precisamente en ello, y es una de sus aportaciones más importantes. 
3. Crear una relación de mutualidad, reciprocidad y reconocimiento mutuo donde compartimos nuestra humanidad.

El poder crear relaciones transformadoras en psicoterapia depende de una de las características centrales de la mente compartida: el poder alinear estados psicológicos con los otros e identificarse con ellos. Para ello es esencial crear un dialogo intersubjetivo donde un "tú y yo" va creando un "nosotros" a través de múltiples interacciones que son particulares a cada relación terapeuta y a veces tardan años en construir.

Varios autores relacionales han abordado este tema. Lewis Aron ha descrito la relación terapéutica como teniendo dos polos (Aron, 1996). Un polo asimétrico creado por el hecho de que los pacientes vienen a terapia para consultar con profesionales que esperan tengan los conocimientos y competencia para ayudarlos. En el mejor de los casos el terapeuta se convierte en una figura de apego y base segura para la exploración de síntomas conflictos de diversa índole que los motivan a buscar ayuda. Durante el curso de psicoterapias más profundas la humanidad de los pacientes y del terapeuta van ir exponiendo sus vulnerabilidades y fuerzas. Estos son momentos donde hay mayores peligros y de grandes oportunidades. Peligro de que la relación terapéutica se deteriore y no se pueda emendar, pero también la oportunidad para profundizar la relación terapéutica creando mayor confianza y sensación de ser visto y comprendido. Otro expresión de esta mutualidad donde compartimos nuestra humanidad con pacientes es lo que Jessica Benjamin llama reconocimiento mutuo (Benjamin, 1992). Para que se pueda dar este reconocimiento mutuo que requiere se logra cuando se crea una tercera dimensión de la intersubjetividad terciara, un "thirdness" en el lenguaje de Benjamin (Benjamin, 2004). Desde el punto de vista que he ido desarrollando, este "tercero" del dialogo intersubjetivo se logra cuando se crea un "nosotros" haciendo algo juntos. En este caso es hacer algo juntos es poder colaborar para lograr un reconocimiento mutuo y con ello poder liberarse de estar atrapado en una dualidad que niega la existencia del otro.

4. Crear perspectivas nuevas con las cuales podemos entendernos a nosotros mismos y entender nuestras relaciones importantes. Esta dimensión es referida en nuestro campo como capacidad de autorreflexión y mentalización, y lo que tradicionalmente ha sido descrito como insight.

Pero que se pueda crear este tercero en la relación terapéutica es necesario el poder tomar la perspectiva del otro y al mismo tiempo mantener una perspectiva propia. Como vimos anteriormente durante el desarrollo normal o típico, esto se logra cuando los niños empiezan a poder colaborar con sus cuidadores (y después con sus compañeros prescolares y escolares) hacia metas en común. Esta toma de perspectivas depende a su vez de la emergencia de la atención conjunta, y lo que Tomasello llama la intencionalidad conjunta que emerge a mediados 
o finales del segundo año de edad. La intencionalidad conjunta permite que los niños pueden colaborar hacia metas comunes e intercambiar roles en estas actividades colaborativas. Esto quiere decir que los niños pueden tomar la perspectiva del otro sin perder de vista la suya propia. Pero esta toma de perspectiva está limitada a interacciones cara-a-cara. Solo años después pueden empezar a imaginarse las perspectivas de los demás sin estar presentes en interacciones conjuntas.

\section{Tener acceso a nuestras capacidades simbólicas y de lenguaje que libera la imaginación.}

Sin la capacidad de acceder a símbolos y sin lenguaje, no habría una "cura por medio de palabras". El lenguaje y los símbolos es una condición necesaria para cualquier tipo de psicoterapia. Nos permite acceder a experiencias encapsuladas en experiencias traumáticas que no pueden ser formuladas de una manera explícita y existen sin poder formularse en un lenguaje corporal sub-simbólico. Sin un leguaje declarativo y simbólico no es posible poder distancia a estas experiencias traumáticas y solo se pueden expresar por medio de re-escenificaciones (enactments) o por medio de imágenes en sueños en alucinaciones o delirios. Pacientes con historias traumáticas están atrapados en su trauma y ven el mundo a través de lentes traumáticos. No tienen la capacidad de poner en perspectiva su experiencia traumática y por lo tanto de mentalizarla y reflexionar sobre ella. No tiene la capacidad de rescatar sus experiencias traumáticas usando la imaginación. Como dijo Steven Mitchell, la psicopatología se puede concebir como una falla de la imaginación (S.A. Mitchell, 1998). Un libro que demuestra como el lenguaje hablado emerge como una tecnología comunicativa social, cuya función es poder usar imaginación en una infinitud de maneras es el libro de Daniel Dor (2017). Dos de las expresiones más bellas de la capacidad liberadora del lenguaje y la imaginación, descrito por pacientes que lograron una transformación profunda de sus experiencias traumáticos que las psicotizaron son los libros escritos por pacientes: Las palabras para decirlo de Marie Cardinal (1983), y Nunca te prometí un jardín de rosas de Hannah Green (1962).

En los últimos años han aparecido muchos artículos y libros que minimizan la importancia del lenguaje hablado a favor del lenguaje subsimbólico de gestos, emociones y del cuerpo. Uno de los representantes más elocuentes de esta posición es Daniel Stern (2004). Al mismo tiempo han aparecido muchas aproximaciones que llegan al trauma por medio del cuerpo, como el trabajo de Peter Levine (2005). Estas aportaciones son importantes y rescatan comunicaciones no verbales para trabajar con el cuerpo con pacientes con historias de trauma, y ha sido una corrección necesaria a posiciones clásicas con un énfasis en el insight como vehículo principal del cambio. Pero estas aportaciones dicotomizan estas dos formas de comunicación y pierden de vista que el lenguaje hablado está lleno de metáforas y expresiones que rescatan las 
comunicaciones subsimbólicas de gestos, emociones y expresiones corporales. Mas aun, el lenguaje hablado y su estructura gramatical compleja emerge en la filogenia como en la ontogenia, de un protolenguaje subsimbólico basado en la mimesis y las emociones. Estas dos formas de comunicación están mucho más integradas de lo sugiere Daniel Stern y muchos otros autores. Dos ejemplos de ver esta integración entre los sistemas subsimbólicos y simbólicos de comunicación son los trabajos de Arnold Modell (2003) y Wilma Bucci (1997, 2005).

Este es un bosquejo de cómo modelo de una mente cooperativa y compartida sirve como una base para las aproximaciones clínicas del psicoanálisis relacional. Espero poder explorar este tema más a fondo en el futuro. Por lo pronto este ensayo está escrito con la intención de proveer los aspectos filogenéticos y ontogenéticos de esta exploración.

\section{REFERENCIAS}

Aiello, L. C., \& Wheeler, P. (1995). The expensive tissue hypothesis: the brain and the digestive system in human evolution. Current Anthropology, 36, 199-221.

Ainsworth, M. D., Blehar, M. C., Waters, E., \& Wall, S. (1978). Patterns of Attachment. A Psychological Study of the Strange Situation. Hillsdale NJ: Lawrence Erlbaum.

Alexander, R. D. (1974). The evolution of social behavior. Annual Review of Ecology and Systematics, $5,325-384$.

Aron, L. (1996). A Meeting of Minds: Mutuality in Psychoanalysis. Hillsdale: NJ: The Analytic Press.

Aron, L. (2003). The Paradoxical Place of Enactments in Psychoanalysis: Introduction. Psychoanalytic Dialogues 13, 623-632.

Bacal, H. A. (1985). Optimal responsivess and the therapeutic process. In A. Goldberg (Ed.), Progress in Self Psychology, vol. I. Hillsdale, NJ: The Analytic Press.

Bacal, H. A. (2006). Specificty Theory. Conceptualizing a Personal and Professional Quest for Therapeutc Possibility. Intrenational Journal of Psychoanalytic Self Psychology, 1, 133-135.

Bader, O. (2020). Being in a Group. the emotional scaffolding of the evolution of collective intentionality. In publication.

Bard, K. A., Myowa-Yamakoshi, M., Tomonaga, M., Tanaka, M., Costall, L., \& Matsuzawa, T. (2005). Group differences in mutual gaze of chimpanzees (Pan troglodytes). Developmental Psychology, 41, 616-624.

Bateson, M. C. (1971). The interpersonal context of infant vocalization. Quarterly Review Rep. Res. Lab. Electronics, 100, 170-176.

Beebe, B., Knoblauch, S., Rustin, J., \& Sorter, D. (2005). Forms of intersubjectivity in infant research and adult treatment New York: Other Press. 
Beebe, B., Rustin, J., Sorter, D., \& Knoblauch, S. (2003). Part III. An expanded view of intersubjectivity in infancy and its applications to psychoanalysis. Symposium on intersubjectivity in infant research and its implications for adult treatment,. Psychoanalytic Dialogues, 13, 805-841.

Benjamin, J. (1992). Recognition and destruction. An outline of intersubjectivity. In N. Skolnick \& S. Warshaw (Eds.), Relational Perspectives in Psychoanalysis (pp. 183-210). Hillsdale; NJ: The Analytic Press.

Benjamin, J. (2004). Beyond Doer and Done to: An Intersubjective View of Thirdness. Psychoanalytic Quarterly, 73, 5-46.

Bjorklund, D. F., \& Rosenberg, J. S. (2005). The Role of Developmental Plasticity in the Evolution of Human Cognition In D. F. Bjorklund \& B. R. Ellis (Eds.), Origins of the Social Brain. Evolutionary Psychology and Child Development (pp. 45-75). New York: Guilford Press.

Boehm, C. (1999). Hierarchy in the Forest. The Evolution of Egalitarian Behavior. Cambridge, MA: Harvard University Press.

Boehm, C. (2012). Moral Origins. The Evolution of Virtue, Altruism, and Shame. New York: Basic Books

Bogin, B., Bragg, J., \& Kuzawa, K. (2014). Humans are not cooperative breeders but practice biocultural reproduction. Annals of Human Biology 41(4), 368-380.

Bowlby, J. (1958). The nature of the child's tie to his mother. International Journal of Psycho-Analysis, $39,350-373$.

Bowlby, J. (1969/1982). Attachment (Vol. I). New York: Basic Books.

Bowlby, J. (1979). The Making and Breaking of Affectional Bonds. London: Tavistock Publications Limited.

Bowlby, J. (1988). A Secure Base. Parent-Child Attachment and Healthy Human Development. New York: Basic Books.

Bowles, S., \& Gintis, H. (2011). A Cooperative Species. Human Reciprocity and it's Evolution. Princeton, $\mathrm{NJ}$ : Princeton University Press.

Boyd, R. (2018). A Different Kind of Animal. How Culture Transforms Our Species Princeton, NJ: Princeton University Press

Boyd, R., \& Richerson, P. J. (2005). The Origin and Evolution of Cultures. New York: Oxford University Press.

Bucci, W. (1997). Psychoanalysis and Cognitive Science. New York: Guilford Press.

Bucci, W. (2005). The interplay of subsymbolic and symbolic processes in psychoanalytic treatment. Psychoanalytic Dialogues., 15, 855-873.

Bullinger, A. F., Kaminiski, J., Zimmerman, F., \& Tomasello, M. (2011). Different social motives in the gestural communication of chimpanzees and human children. Developmental Science, 14, 58-68.

Burkart, M. J., Hrdy, S. B., \& Van Schaic, C. P. (2009). Cooperative Breeding and Human Cognitive Development Evlutionary Anthropology 18, 175-186. 
Burkart, M. J., \& Van Schaik, C. P. (2010). Cognitive consequences of cooperative breeding in primates? Animal Cognition, 13, 1-19. doi:10.1007/s10071-009-0263-7

Cardinal, M. (1983). The Words to Say It. Cambridge, Massachudetts: VanVacior \& Goodheart.

Carpenter, M., \& Call, J. (2009). Comparing the imitative skills of children and nonhuman apes. Revue de primatologie (online). Retrieved from http://primatolgie.revues.org263.

Carpenter, M., \& Call, J. (2013). How joint is joint attention of apes and human infants? In H. S. Terrace \& J. Metcalfe (Eds.), Agency and joint attention (pp. 49-61). New York: Oxford University Press.

Carpenter, M., \& Liebal, K. (2011). Joint Attention, Communication, and Knowing Together in Infancy. In A. Seemann (Ed.), Joint Attention: New Developments in Psychology, Pilosophy and Social Neuroscience (pp. 159-181). 2011: The MIT Press.

Carpenter, M., Tomasello, M., \& Striano, T. (2005). Role reversal imitation and language in typicallydeveloping infants and children with autism. Infancy, 8, 253-278.

Cavalli-Sforza, L. L., \& Feldman, M. W. (1981). Cultural Transmission and Evolution. Princeton: Princeton University Press.

Champagne, A., \& Curley, J. P. (2009). Epigenetic mechanisms mediating the long-term effects of maternal care on development. Neuroscience and Biobehavioral Reviews, 33, 593-60o.

Chapais, B. (2008). Primeval Kinship. How Pair Bonding Gave Birth to Human Society. Cambridge, MA: Harvard University Press.

Cortina, M. (2013). The Use of Attachment Theory in the Clinical Dialogue with Patients Pschodynamic Psychiatry, 41, 397-418.

Cortina, M. (2017). Adaptive flexibility, Cooperation, and Prosocial Motivations: The Emotional Foundations of Becoming Human. Psychoanalytic Inquiry, 37, 433-435.

Cortina, M. (2018a). Avances Clínicos de la Teoría de Apego en los Últimos 25 años Aperturas Psicoanaliticas 53, 1-30.

Cortina, M. (2018b). El apego visto desde un contexto de una mente cooperativa y compartida In S. Gojman-de Millan, C. Herreman, \& A. Sroufe (Eds.), La Teoria de Apego. Investigacion e Intervención en Distintos Contectos Socioculturales (pp. 124-167). Cuidad de México Fondo de Cultura Económico.

Cortina, M., \& Liotti, G. (2007). New approaches to understanding unconscious processes: Implicit and explicit memory systems. International Forum of Psychoanalysis, 16, 204-212.

Cortina, M., \& Marrone, M. (2017). Apego y psicoterapia, un paradigma revolucionario. Madrid, España: Psimática, Editorial.

Csibra, G., \& Gergely, G. (2009). Natural Pedagogy. Trends in Cognitive Science, 13, 148-153.

Decety, J. (2005). Perspective Taking as the Royal Avenue to Empathy. In B. F. Malle \& S. D. Hodges (Eds.), Other Minds. How Humans Bridge the Devide Between Self and Others.

deMenocal, P. B. (2004). African climate change and founal evolution during the PliocenePliestocene transition Earth and Planetary Science Letters, 230, 3-24. 
Dor, D. (2017). The intruction of Imagination. Language as a Social Communication Technology New York: Oxford University Press

Fairbairn, W. R. D. (1952). Psychoanalytic Studies of the Personality. London: Routledge.

Flückiger, C., Del Re, A. C., Wampold, B. E., \& Horvath, A. O. (2018). The Alliance in Adult PsychotherapyA Meta-Analytic Synthesis. Psychotherapy, 55, 316-340.

Fonagy, P., Bateman, A., \& Luyten, P. (2012). Handbook of Mentalizing in mental health practice. Arlington, VA: American Psychiatric Publishing, Inc.

Fosshage, J. (2005). The explicit and implicit domains in psychoanalytic change. Psychoanalytic Inquiry, 25, 511-539.

Freud, S. (1913). Totem and Taboo. SE, 20, 131-160.

Freud, S. (1930). Civilization and its Discontents (Vol. 21 Standard Edition). London: The Hogarth Press.

Fromm, E. (1945). El Miedo a La Libertad. Busnos Aires. Argentina Piados

Fromm, E. (1947). Man for Himself. An Inquiry into the Psychology of Ethics. New York: Holt, Rinehart \& Winston.

Fromm, E. (1955). The Sane Society. New York: Holt, Rinehart \& Winston.

Fromm, E. (1970). The Crisis of Psychoanalysis. New York: Holt, Rinehart \& Winston.

Fromm, E. (1973). The Anatomy of Human Destructiveness. New York: Holt, Rinehart and Winston.

Fuentes, A. (2017). The Creative Spark. How imagination made Humans Exceptional New York Dutton.

Gallagher, S. (2011). Interactive coordination in joint attention. In A. Seemann (Ed.), Joint Attention. New Developments in Psychology, Phylosophy of Mind and Social Neuroscience (pp. 293-304). Cambridge, MA: MIT Press.

Gallese, V. (2002). The manifold nature of interpersonal experience: the quest for common mechanisms. [E- Publication].

Gibbons, A. (2008). The Birth of Childhood. Science, 322, 1040-1042.

Gibbons, A. (2017). Oldest member of our species discovered in Morroco Science 356, 993-994.

Gintis, H. (2003). The Hitchhiker Guide to Altruism: Gene-culture Coevolution, and the Internalization of Norms Journal of Theoretical Biology, 220, 407-418.

Gottlieb, G. (2007). Probabilistic epigenesis. Developmental Science, 1-11.

Gould, S. J. (1977). Ontogeny and Phylogeny. Cambridge, Massachusetts: Belknap Press.

Gould, S. J., \& Lewontin, R. C. (1979). The spandrels of San Marcos and the Panglosian paradigm: a critique of the adatationist program Procedures of The Royal Society of London, 205, 581-598.

Gräfenhain, M., Behne, T., Carpenter, M., \& Tomasello, M. (2009). Young Children's Understanding of Joint Commitments. Developmental Psychology, 54, 1430-1443.

Green, H. (1962). I never promised you a rose garden. New York 
Greenberg, J. R., \& Mitchell, S. A. (1983). Object Relations in Psychoanalytic Theory New York: Harvard University Press.

Grossmark, R. (2016). Pyschoanalytic Companioning. Psychoanalytic Dialogues, 26, 698-712.

Guntrip, H. (1971). Pyschoanalytic Theory, Therapy and the Self. New York: Basic Books.

Hamilton, W. D. (1963). The evolution of altruistic behavior. The American Naturalist, 97, 354-356.

Hamilton, W. D. (1964). The genetical evolution of social behavior. Journal of Theoretical Biology, 7, 1-16.

Hamlin, J. K., \& Wynn, K. (2011). Five and 9-month-old infants prefer prosocial to antisocial others. Cognitive development, 26, 30-39.

Hamlin, J. K., Wynn, K., \& Blomm, P. (2010). 3-Month-Olds Show a Negative Bias in Social Evaluations. Developmental Science, 13, 923-939.

Hare, B., \& Tomasello, M. (2004). Chimpanzees are much more skillful in competitive than in cooperative cognitive tests. Animal Behavior, 68, 571-581.

Henrich, J. (2016). The Secret of our Sucsess. How Culture is Driving Human Evolution, Domesticating our Species and Making us Smarter Princeton, New Jersey: Princeton University Press.

Henrich, N., \& Henrich, J. (2007). Why Humans Cooperate. A Cultural and Evolutionary Explanation. Oxford: Oxford University Press.

Hepach, R., Vaish, A., \& Tomasello, M. (2012). Young children are intrinsically motivated to see others helped. Psychological science, 23, 957-972.

Hepach, R., Vaish, A., \& Tomasello, M. (2013). A New Look ay Children's Prosocial Motivation. Infancy, 18, 67-90.

Hermann, E., Call, J., Hernández-Lloreda, M. V., Hare, B., \& Tomasello, M. (2007). Humans Have Evolved Specialized Skills of Social Cognition: The Cultural Intelligence Hypothesis Science, 317, 1360-1366.

Hill, K. R., R.S., W., Boziecocich, M., Elder, J., Headland, T., Hewlett, B., . . Wood, B. (2011). CoResidence Patterns in Hunter-Gatherer Societies Show Unique Human Social Structure. Science, 331, 1286-1289.

Hobson, R. P. (2004). The Cradle of Thought. Exploring the Origins of Thinking. Oxford, UK: Oxford University Press.

Hobson, R. P., \& Hobson, J. (2011). Joint Attention or Joint Engagement? Insights from Autism. In A. Seemann (Ed.), Joint Attention. New Development in Psychology, Philosophy of Mind, and Social Neuroscience (pp. 115-135). Cambridge. Massachusetts: The Mit Press.

Hoffman, I. Z. (1998). Ritual and Spontaniety in the Psychoanalytic Process. A dialectical -Constructivist View. Hillsdale, NJ: The Analytic Press.

Horney, K. (1937). The Nuerotic Personality of Our Time New York: W.W, Norton.

Hrdy, S. (1999). Mother Nature. Maternal Instincts and how they Shape the Human Species. New York: Ballantine Books. 
Hrdy, S. (2009). Mothers and Others. The Evolutionary Origins of Mutual Understanding. Cambridge MA: The Belknap Press

Hrdy, S. (2016). Development and Social Selection in the Emergence of "Emotionally Modern" Humans. In X. L. Meehan \& A. N. Crittenden (Eds.), Origins and Implications of the Evolution of Childhood. (pp. 57-91). Santa Fe, NM: SAR Press.

Jablonka, E., \& Lamb, M. L. (2005). Evolution in Four Dimensions. Genetic, Epigenetic, Behavioral, and Symbolic. Cambridge, Massachusetts: A Gradford Book. MIT Press.

Jacobs, T. S. (1986). On Countertransference Enactments Journal of the American Psychoanalytic Association, 34, 289-307.

Jensen, K., Call, J., \& Tomasello, M. (2007). Chimpanzees are Rational Maximizers in the Ultimatum Game. Science, 318, 107-108.

Johnson, S., \& Whiffen, V. E. (2003). In S. Johnson \& V. E. Whiffen (Eds.), Attachment Processes in Couple and Family Therapy. (pp. 232-260). New York: Guilford.

Kohut, H. (1977). The Restoration of the Self. New York: International University Press.

Kohut, H. (1984). How Does Analysis Cure? Chicago: University of Chicago Press.

Köymen, B., D.A, E., Warneken, F., Lievan, E., Rakoczy, H., \& Tomasello, M. (2014). Children's Norm Enforcement in Their Inteeractions With Peers. Child Development, 85, 1108-1122.

Laland, K. N. (2017). Darwin's Unfinished Symphony. How Culture Made the Human Mind Prinecetion, NJ Princeton

Laland, K. N., Uller, T., Feldman, W. M., Sterelny, J., Muller, G. B., Moczek, A., . . Odling-Smee, J. (2015). The extended evlutionary synthesis: Its structure, assumptions and predictions. Proceedings of The Royal Society B, 282(20151019). doi:dx.doi.org/10.1098/rspb.2015.1019

Leimar, O., \& Hammerstein, P. (2001). Evolution of cooperation through indirect reciprocity. Proc. $R$. Soc. Lond. $B, 268,745$.

Levine, P. (2005). Healing Trauma. A Pioneering Program for Restoring the Wisdom of Your Body. Bolder, CO: Sounds True.

Levy, R. A., \& Ablon, J. S. (Eds.). (2009). Handbook of Evidence-Based Pychodynamic Psychotherapy. Bridging the Gap Between Science and Practice. New York: Humana Press.

Lewontin, R. C. (1978). Adaptation. Scientific American 239, 156-169.

Lichtenberg, J. D., Lachmann, F. M., \& Fosshage, J. I. (1996). The Clinical Exchange. Techniques Derived from Self and Motivational Systems Hillsdale, NJ: The Analytic Press.

Liszkowski, U., Carpenter, M., Henning, A., Striano, T., \& Tomasello, M. (2004). Twelve-month-olds point to share attention and interest. Developmental Science, 7, 297-307.

Marrone, M. (2001). La Teoria de Apego. Un enfoque actual. Madrid: Psimatica.

McBrearty, S. (2007). Down with the revolution. In K. B. P. Mellars, O. Bar-Yosef, C. Stringer (Ed.), Rethinking the human revolution. Cambridge UK: McDonald Institute Monographs. 
McBrearty, S., \& Brooks, A. S. (2000). The revolution that wasn't: a new interpretation to the origin of modern human behavior. Journal of Human Evolution, 39, 453-563.

Meltzoff, A. N. (1999). Origins of theory of mind, cognition and communication. Journal of Communication Disorders, 251-268.

Meltzoff, A. N. (2005). Imitation and Other Minds. The "Like Me" hypothesis. In S. Hurley \& N. Chater (Eds.), Perspective on Imitation. From Neuroscience to Social Science. (Vol. 2, pp. 55-57). Cambridge, MA: MIT Press.

Meltzoff, A. N. (2007). 'Like me': a foundation for social cognition Developmental Science 19, 126-134.

Meltzoff, A. N., \& Gopnik, A. (1993). The role of imitation in understanding persons and theory of mind In S. Baron Cohen, H. Tager-Flushberg, \& G. Cohen (Eds.), Understanding Other Minds: Perspectives from Autism (pp. 335-366). New York: Oxford University Press.

Miller, G. (2007). Special Section on Social Cognition. All Together Now--Pull Science, 317, 1338-1340.

Mitchell, S. A. (1988). Relational Concepts in Psychoanalysis. Cambridge, MA: Harvard University Press.

Mitchell, S. A. (1998). Attachment Theory and the Psychoanalytic Tradition: Reflections on Human Relationality. British Journal.of Psychotherapy, 15, 177-193.

Mitchell, S. A., \& Aron, L. (Eds.). (1999). Relational Psychoanalysis. Hillsdale, NJ: The Analytic Press.

Modell, A. H. (2003). Imagination and the meanigful brain Cambridge: MIT Press.

Mohl, H., \& Tomasello, M. (2007). How 14-- and 18-- month-olds know what others have experienced. Developmental psychology, 43, 309-317.

Moll, H., \& Meltzoff, A. N. (2011). Joint Attention as the Fundamntal Basis of Understanding Perspectives. In A. Seemann (Ed.), Joint Attention (pp. 393-413). Camebridge, Massachusetts: MIT Press.

Norcross, J. C. (2002). Psychotherapy. Relations that Work. New York: Oxford University Press.

Nowak, M. A., \& Highfield, R. (2011). Super Cooperators. Altruism, Evolution, and Why We Need Others to Succeed. New York: Free Press.

Onishi, K. H., \& Baillargeon, R. (2005). Do 15-month-old infants understand false beliefs? Science, $308,255-258$.

Panksepp, J. (1998). Affective Neuroscience. New York: Oxford University Press.

Perner, J., Ruffman, T., \& Leekam, S. (1994). Theory of mind is contagious: You catch it from your sibs. Child Development, 63, 1228-1283.

Potts, R. (1999). Variability selection in hominid evolution. Human Evolution, 7, 81-96.

Reddy, V. (2008). How Infants Know Minds. Cambridge, MA: Harvard University Press.

Renik, O. (1999). Playing One's Cards Face up in Analysis: An Approach to the Problem of SelfDisclosure. Psychoanalytic Quarterly, 68, 521-539

Renik, O. (2007). Intersubjectivity, Therapeutic Action, and Analytic Technique. . Psychoanal Quarterly, 76S(Supplement):, 1547-1562. 
Richerson, P., \& Boyd, R. (2005). Not by genes alone. Chicago: The University of Chicago Press.

Richerson, P., \& Boyd, R. (2013). Rethinking Paleoanthroplogy. A world queerer than we supposed. In G. Hatfield \& H. Pittman (Eds.), Evolution of Mind. Brain, and Culture (pp. 263-302). Philadelphia, PA: University of Pennsylvania Museum of Archeology and Anthropology.

Ringstrom, P. A. (2001). Cultivating the Improvisational in Psychoanalytic Treatment. Psychoanal. Dialloques, 11, 727-754.

Rizzolatti, G., Fadiga, L., Gallese, V., \& Fogassi, L. (1996). Premotor cortex and the recognition of motor actions. Cognitive Brain Research, 3, 131-141.

Schmidt, M. F. H., Rakocky, H., \& Tomasello, M. (2012). Young children enforce social norms selectively depending on the violator's group affiliation. Cognition, 124, 325-333.

Schmidt, M. F. H., \& Tomasello, M. (2012). Young children enforce social norms. Currenet directions in psychological science 21, 223-226.

Schore, A. L. (2009). Attachment trauma and the developing right brain: Origins of pathological dissociation

In P. F. Dell \& J. A. O'Neil (Eds.), Dissociation and the dissociative disorders: DSM-V and beyond (pp. 259-276). New York: Rutledge. .

Siegel, D. J. (1999). The Developing Mind, How Relationships and the Brain Interact to Shape who we are. New York: The Guilford press.

Sober, E., \& Wilson, D. S. (1998). Unto Others: The Evolution and Psychology of Unselfish Behavior. Cambridge, Massachusetts: Harvard University Press.

Sroufe, A. (2016). The Place of Attachment in Development. In J. Cassidy \& P. R. Shaver (Eds.), Handbook on Attachment. Theory, Resrach, and Clinical Applications (pp. 997-1011). New York: : The Guilford Press.

Sroufe, L. A. (1996). Emotional Development. The Organization of Emotional Life in the Early Years. New York: Cambridge University Press.

Sroufe, L. A., Carlson, E. A., Levy, K. A., \& Egeland, B. (1999). Implications of attachment theory for devlopmental psychopathology Development and Psychopathology 11, 1-13.

Sroufe, L. A., Egeland, B., Carlson, E., \& Collins, W. A. (2005). The Development of the Person. The Minnesota Study of Risk and Adaptation from Birth to Adulthood New York: The Guilford Press.

Sroufe, L. A., Egeland, B., \& Carlson, E. A. (1999). One social world. The integrated development of parent-child and peer relations. In W. A. Collins \& B. Laursen (Eds.), The Minnesota Symposia on Child Psychology. Vol. 30. Relationships as Developmental Contexts (pp. 241-261). Mahwah, NJ: Erlbaum.

Sterelny, K. (2012). The Evolved Apprentice. How Evolution Made Humnans Unigue. Cambridge, Massachusetts: MIT.

Sterelny, K. (2016). Cumulative Cultural Evolution and the Origins of Language Bilogical Theory

Stern, D. (1985). The Interpersonal World of the Infant. New York: Basic Books. 
Stern, D. (2004). The Present Moment in Psychotherapy and Everyday Life. New York: W. W. Norton \& Company.

Stern, D. (2006). Some Implications of Infant Research for Psychoanalysis. In A. M. Cooper (Ed.), Contemporary Psychoanalysis in America (pp. 637-641). Washington, D.C.: American Psychiatric Publishing, INC.

Suddendorf, T., \& Corballis, M. C. (1997). Mental mind travel and the evolution of the human mind. Genetic, Social and General Psychology, 123, 133-167.

Sullivan, H. S. (1953). The Intepersonal Theory of Psychiatry. New York: W. W. Norton.

Sulloway, F. J. (1979). Freud. Biologist of the Mind. New York: Basic Books.

Svetolova, M. S., Nichols, S., \& Bronwell, C. (2010). Todlers prosocial behavior: Fromm instrumental to empathic to altrusitic helping. Child Development, 1814-1817.

Tolpin, M. (2002). Chapter 11 Doing Psychoanalysis of Normal Development: Forward Edge Transferences. Progress in Self Psychology, 18:167-190, 18, 167-190.

Tomasello, M. (2014). A Natural History of Human Thinking. Cambridge, Massachusetts: Harvard University Press.

Tomasello, M. (2016). The Natural History of Human Morality. Cambridge, MA: Harvard University Press.

Tomasello, M. (2019). Becoming Human. A Theory of Ontogeny Cambridge, Massachusetts: Harvard University Press.

Tomasello, M., Carpenter, M., Call, J., Behne, T., \& Henrike, M. (2005). Understanding and sharing intentions: the origins of cultural cognition. Behavioral and Brain Sciences, 28, 675-735.

Tomasello, M., Melis, A. P., Tennie, C., Wyman, E., \& Herrmann, E. (2012). Two Key Steps in the Evolution of Human Cooperation. Current Anthropology, 53, 673-692.

Trevarthen, C. (1977). Descriptive analysis of infant communication. In H. Schaffer (Ed.), Studies in Mother-Infant Interactions (pp. 227-270). London: Academic Press.

Trevarthen, C. (1979). Communication and cooperation in early infancy. A description of primary intersubjectivity. In M. Bullowa (Ed.), Before Speech: The Beginning of Human Communication. (pp. 321-346). London: Cambridge University Press.

Trevarthen, C. (1980). The foundations of intersubjectivity: The Social Foundations of Language and Thought. In D. R. Olsen (Ed.), The Social Foundations of Language and Thought (pp. 316-342). New York: W.W. Norton.

Trevarthen, C. (1988). Universal Cooperative Motives. How Children begin to know language and skills and culture. In G. Jahoda \& I. M. Lewis (Eds.), Acquiring Culture: Cross Cultural Studies in Child Development (pp. 37-90). London: Croom Helm.

Trivers, R. L. (1971). The Evolution of Reciprocal Altruism. The Quarterly Review of Biology 46, 35-37.

Tronick, E. (2007). The Neurobehavioral and Socio-Emotional Development of Infants and Children. New York W.W. Norton 
Tronick, E., Als, H., Adamson, L., Wise, E., \& Brazelton, T. B. (1978). The infant's response to entrapment between contradictory messages in face-to-face interactions. Journal of the American Academy of Child and Adolescent Psychiatry, 17, 1-13.

Warneken, F., Hare, B., Melis, A. P., Hanus, D., \& Tomasello, M. (2007). Spontaneues Altrusim by Chimpanzees and Young Chuldren. PLOS Biology. doi:10.137/journal.pbio 0050184

Warneken, F., \& Tomasello, M. (2006). Altruistic Helping in Human Infants and Young Chimpanzees. Science, 311, 1301-1304.

Warneken, F., \& Tomasello, M. (2007). Spontaneous altruism by young children and chimpanzees. PLOS Biology, 5, 1414--1420.

Warneken, F., \& Tomasello, M. (2008). Extrinsic rewards undermine altruistic tendencies in 20month-olds. Developmental Psychology, 44, 1785-1788.

Warneken, F., \& Tomasello, M. (2009). Varieties of Altruism in children and chimpanzees. Trends in Cognitive Science, 13, 397-402.

Wellman, H. M., Cross, D., \& Watson, J. (2001). Meta-analysis of theory-of-mind development. The truth about false belief. Child Development, 72, 655-684.

West-Eberhard, M. J. (2003). Developmental Plasticity and Evolution. Oxford: Oxford University Press.

Williams, E. (1966). Adaptation and Natural Selection. Oxford, UK: Oxford University Press.

Wilson, D. S., \& Wilson, E. O. (2007). Rethinking the theoretical foundations of sociobiology Quarterly Review of Biology, 327-328.

Wilson, E. O. (2012). The Social Conquest of Earth. New York: Liveright Publishing Company.

Wilson, E. O. (2014). The Meaning of Human Existence. New York: W.W. Norton.

Winnicott, D. W. (1969). The use of an object. International Journal of Psycho-Analysis, 50, 711-716.

Wrangham, R. (2009). Catching fire. How cooking made us human. New York: Basic Books.

Original recibido con fecha: 17/10/2019 Revisado: 8/03/2020 Aceptado: 15/03/2020

NOTAS:

${ }^{1}$ El termino técnico para designar especies ultrasociales es eusociabilidad. Solo 20 especies de más de 1 millón
de insectos adquieren este nivel eusocial. Entre los mamíferos nuestra especie es la única que califica como
eusocial (E. O. Wilson, 2012, 2014)
${ }^{2}$ Tanto las ideas de Lamarck como las de Haeckel quedan totalmente desacreditadas con el descubrimiento de
las leyes de herencia por Mendel y la "gran síntesis" del siglo 20 centrado en un análisis genético. Pero resulta
que había un ápice de verdad en que algunas características pueden por mecanismo epigenéticos ser heredados
(Champagne \& Curley, 2009). Y aunque no hay una recapitulación mecánica directa como lo pensó Haeckel, si
hay relaciones complejas entre la evolución y el desarrollo (ver a continuación).
3 Robert Trivers intenta remediar este problema dentro del marco genético de la gran síntesis proponiendo la
idea de una reciprocidad altruista (Trivers, 1971). La idea es que una reciprocidad de conductas altruistas de

(c) Derechos reservados/Copyright de Clínica e investigación Relacional y los autores. Prohibida la reproducción total o parcial sin autorización expresa. Este material es para uso científico y profesional exclusivamente y puede contener información clínica sensible. Los editores no se responsabilizan de los contenidos de los autores. Dirigir las consultas sobre derechos y autorizaciones a ceir@psicoterapiarelacional.es 
miembros que no están relacionados genéticamente evoluciono por reciprocidad: "tú me ayudas a mí y yo te ayudo a ti". El problema con esta propuesta es que este tipo de reciprocidad es casi exclusiva de nuestra especie. Para que la reciprocidad altruista puede evolucionar tienen que haber ya sea sanciones para los que violan esta mutualidad. o normas sociales que la apoyen.

${ }^{4}$ Esto no quiere decir que en nuestra especie dejemos de tener preferencia marcadas por figuras de apego especificas en momentos de estrés o peligro. A partir de los 9 o 12 meses de año los infantes muestran una preferencia marcada hacia una figura de apego principal, con una a dos figuras secundarias.

5 Bogin y sus colaboradores han propuesto una modificación al nombre de la propuesta de Hrdy basado en el hecho de que, en grupos humanos, las cuidadores o cuidadoras (alomadres) no necesariamente están genéticamente relacionados como es el caso de todas las especies donde existe la crianza cooperativa (cooperative breeding). Por ello prefieren el termino de reproducción biocultural "biocultural reporduction" (Bogin et al., 2014). Es un buen punto consistente con la observación de Hill y sus colaboradores. En una muestra muy grande de grupos de cazadores y recolectores nómadas estudiados, la mayoría no están relacionados genéticamente (Hill et al., 2011). Bogin y colaboradores también aducen que el tener múltiples cuidadores redistribuyo el costo energético de criar niños, y esta energía extra se canalizo en poder tener vidas mas largas. Para fines de este ensayo adopto el nombre de crianza cooperativa o biocultural para tomar en cuenta la modificación de Bogin.

${ }^{6}$ La monogamia es una adaptación poco frecuente, y solo ocurre un $5 \%$ de todas las especies de mamíferos y de algunas especies de pájaros.

7 También es notorio que, en contraste con muchas otras especies de mamíferos, la preferencia marcada hacia figuras de apego primarias en situaciones nuevas o cuando están estresados no se empieza a expresar hasta muy tarde en el desarrollo, los 8 o 9 meses de edad. En contaste, nuestros parientes más cercanos los chimpancés y bonobos, se refugian y agazapan de sus madres poco después de nacer. 